\title{
Guideline of inductively coupled plasma mass spectrometry "ICP-MS": fundamentals, practices, determination of the limits, quality control, and method validation parameters
}

\author{
Mostafa F. Al-Hakkani ${ }^{1}$ (i) \\ (c) Springer Nature Switzerland AG 2019
}

\begin{abstract}
The objective of this work is, the introduction of a quick guideline for the ICP-MS users to have a look on the theory, composition, some of the quality control and quality assurance definitions and demands, reagents preparation, detection limits calculation, method validation parameters of ICP-MS method of analysis.
\end{abstract}

Keywords ICP-MS · Isotopes $\cdot \mathrm{LOD} \cdot \mathrm{LOQ} \cdot$ Validation

\section{Introduction}

At the last 3 decades, the Inductively Coupled Plasma Mass Spectrometry (ICP-MS) became the best tool in trace elemental determination Fig. 1. ICP-MS is an analytical technique used for elemental determinations; about 80 elements from the periodic tables as in Fig. 2. The technique was commercially introduced in 1983. ICP-MS importance lies in its instrument detection limits are at or below the part per trillion (ppt, $10^{-12}$ ) and isotopic analysis ratios can be realized easily. So, It can easily determine the most abundant of the natural isotopes for each element as in Fig. 2 revealed in each element block which represented as bars.

The ICP-MS instrument uses the inert argon gas as a plasma source to generate the ionization state for elements; Mass spectrometer (MS) used in parallel with a quadrupole mass filter for separating the produced ions for detection and investigation. Analytes concentration of most elements in the periodic table could be determined at ppb and ppt levels. ICP-MS used for qualitative, isotopes ratio, semi-quantitative analysis, and quantitative analysis. Also, it can determine the ratios of isotopic in liquid
masS Spectrometry "ICP-MS":
of the limits, quality Control,
deline for the ICP-MS users to have a look on the theory,
MS definitions and demands, reagents preparation, detec-
In generaf of analysis.
the presence of some of the elements or not in the sam-
ple matrixes without completely calibration standard
sequence. Also, it supplies us with valuable information
about the composition and elemental concentration by
fast scanning comparing with one standard at least. The
semi-quantitative analysis provides also with the predict-
able interferences in the introduced unknown sample.
samples like water, wastewater, extracts and digested
material in a liquid state. The sample was introduced by a
peristaltic pump with a nebulizer system which converts
the sample to an aerosol, then it passes into a spray cham-
ber and introduced into the plasma.

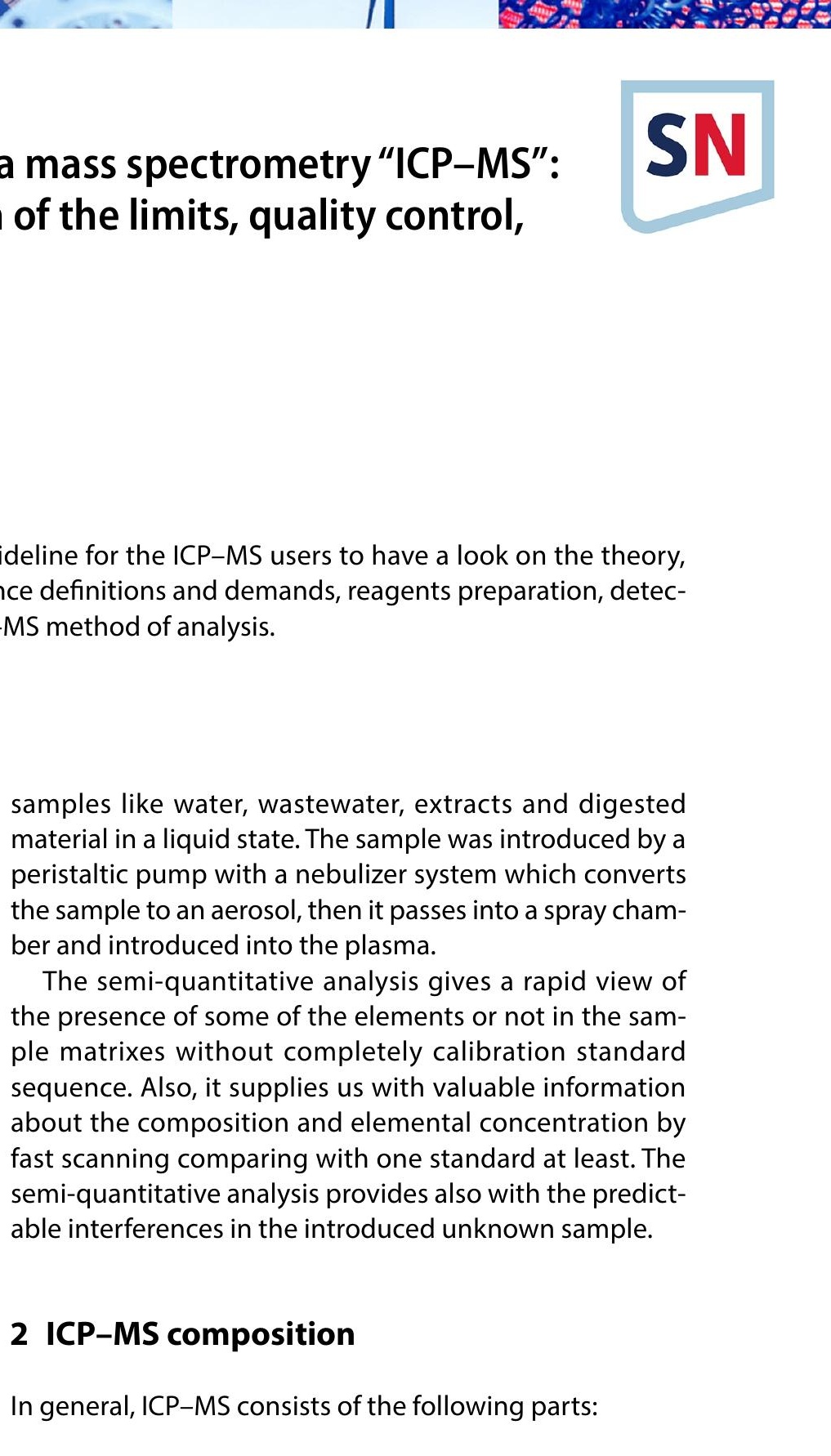

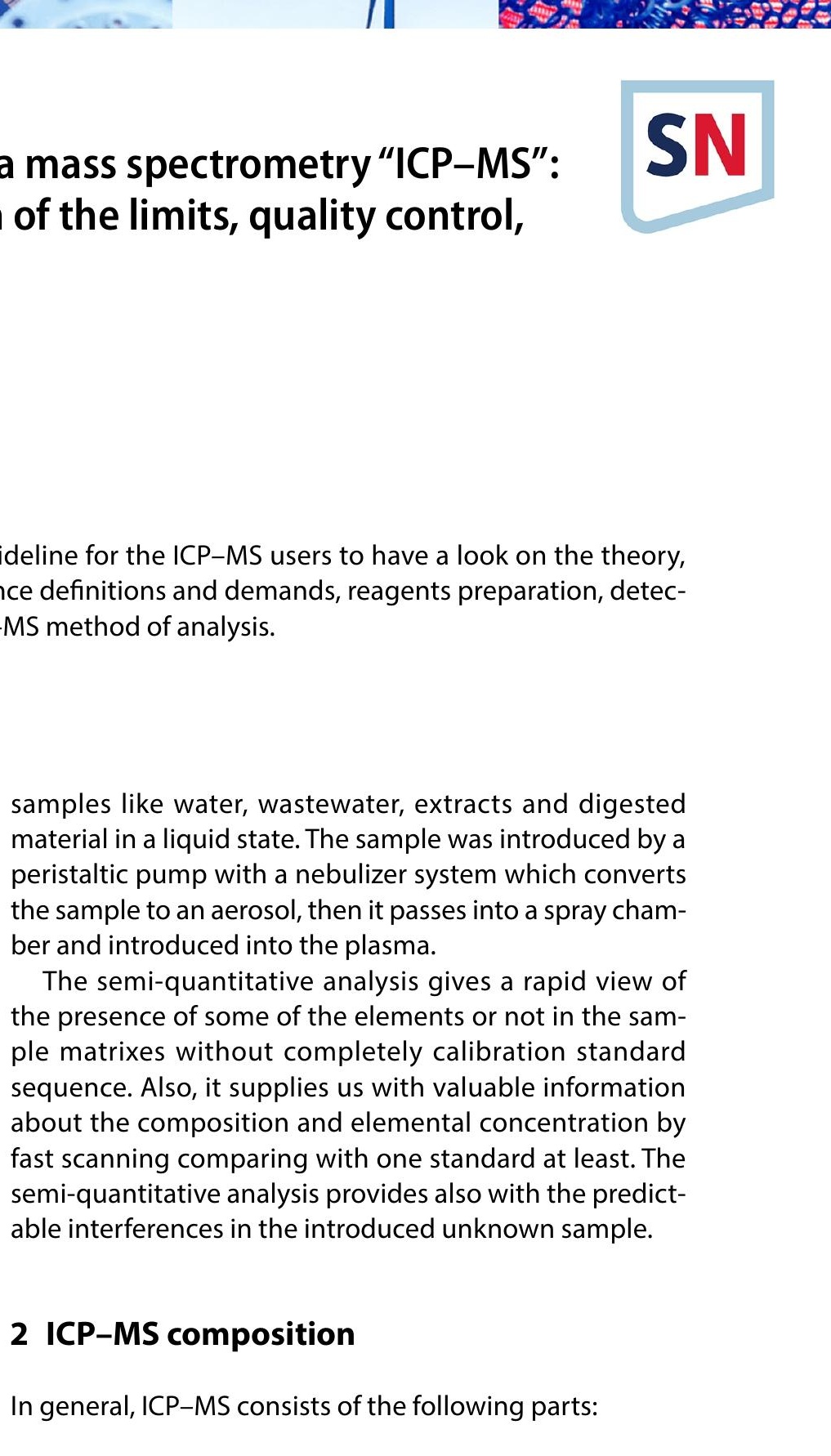

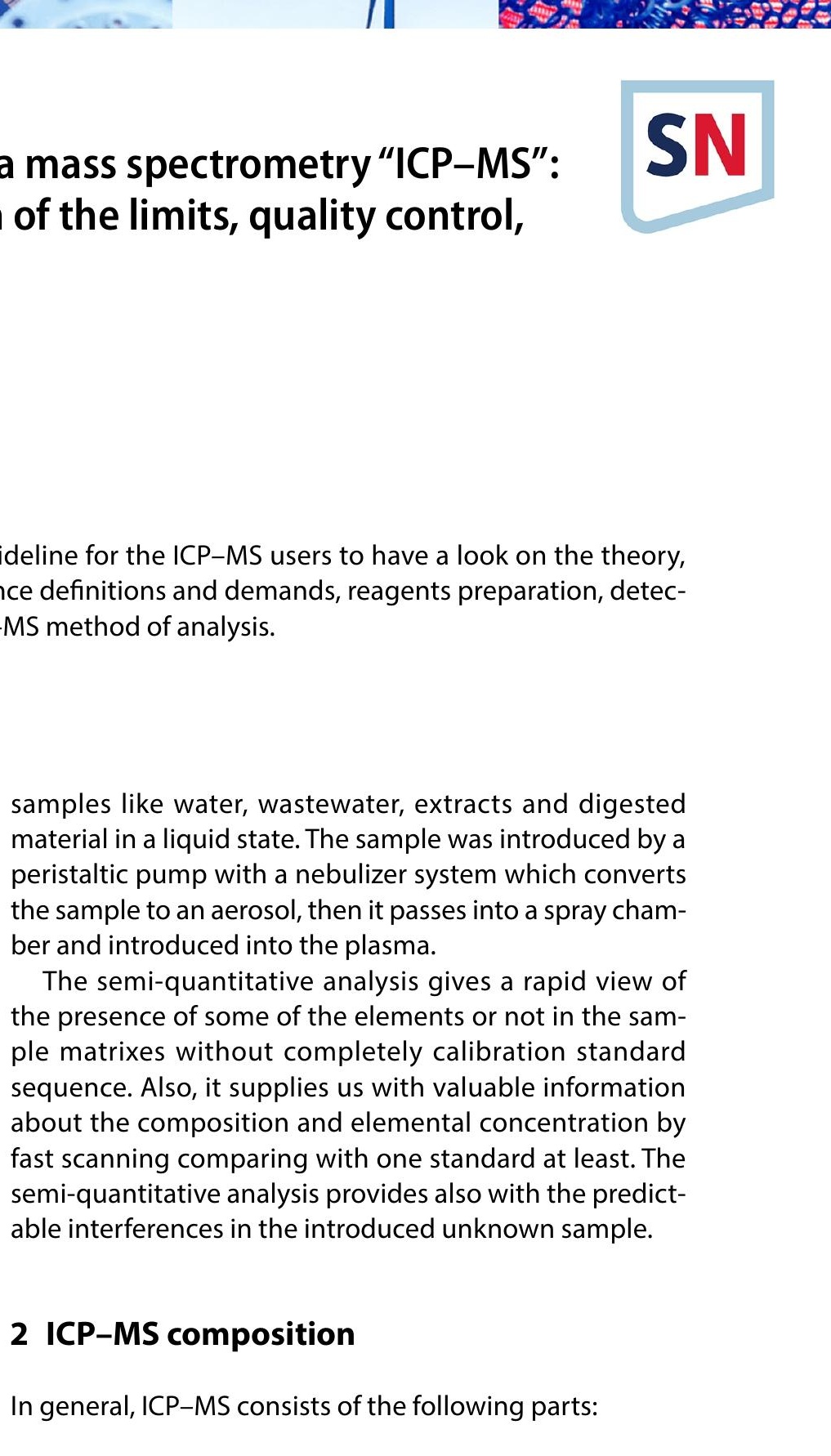

MasS Spectrometry "ICP-MS":
of the limits, quality Control,
ICline for the ICP-MS users to have a look on the theory,
MS method of analysis.
In general, ICP-MS consists of the following parts:
the presence of some of the elements or not in the sam-
ple matrixes without completely calibration standard
sequence. Also, it supplies us with valuable information
about the composition and elemental concentration by
fast scanning comparing with one standard at least. The
semi-quantitative analysis provides also with the predict-
able interferences in the introduced unknown sample.
samples like water, wastewater, extracts and digested
material in a liquid state. The sample was introduced by a
peristaltic pump with a nebulizer system which converts
the sample to an aerosol, then it passes into a spray cham-
ber and introduced into the plasma.
The semi-quantitative analysis gives a rapid view of

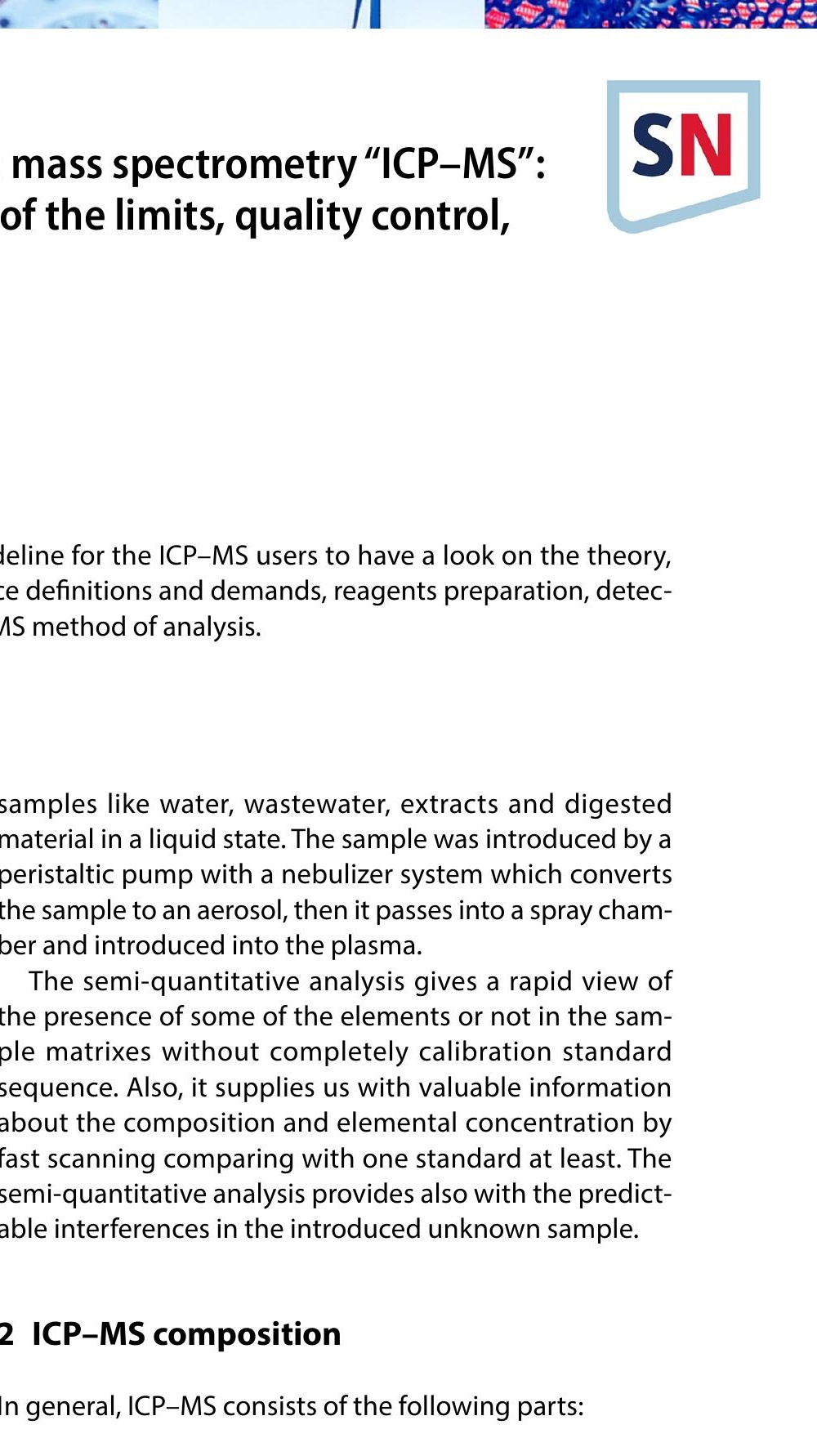

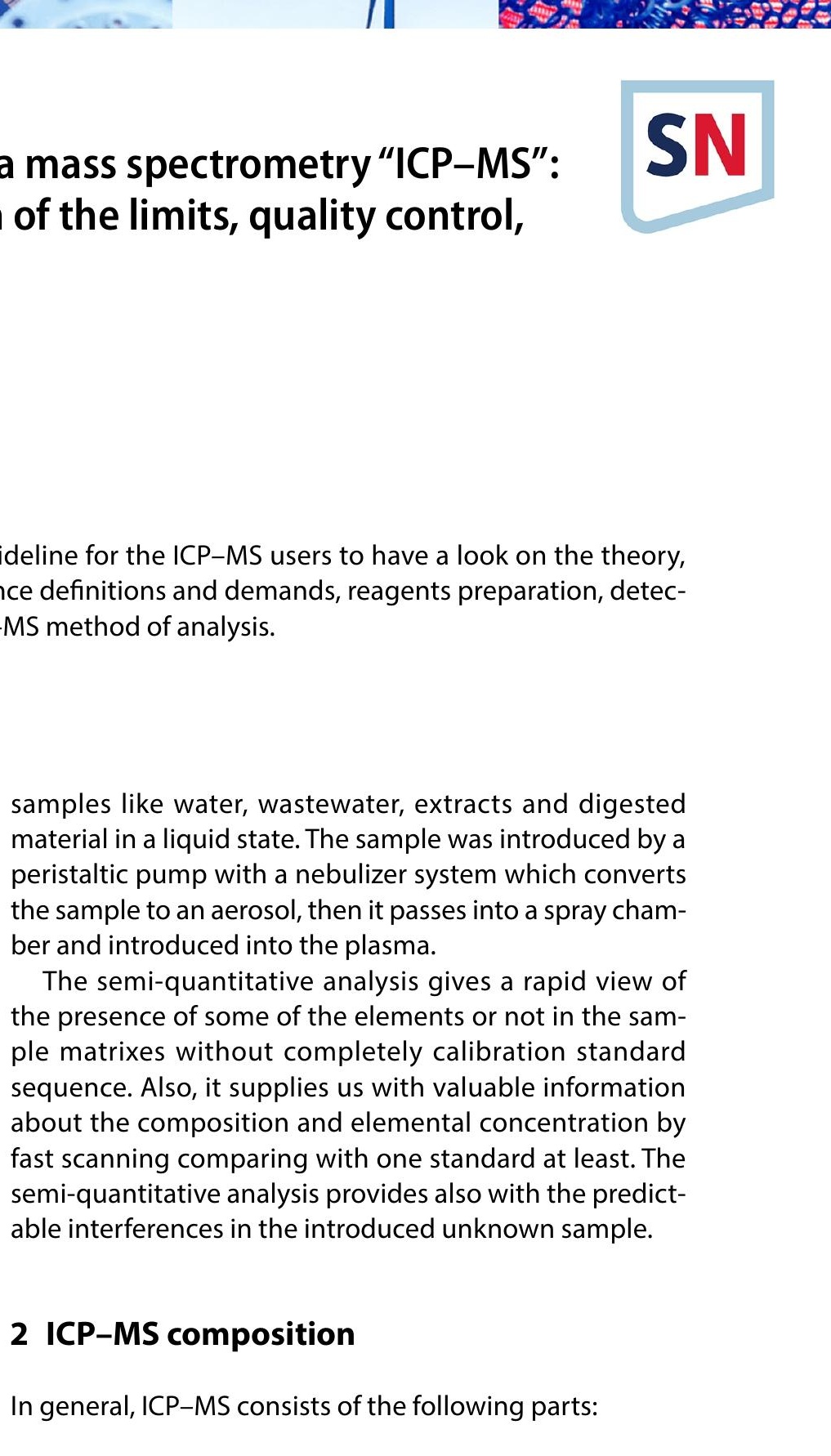

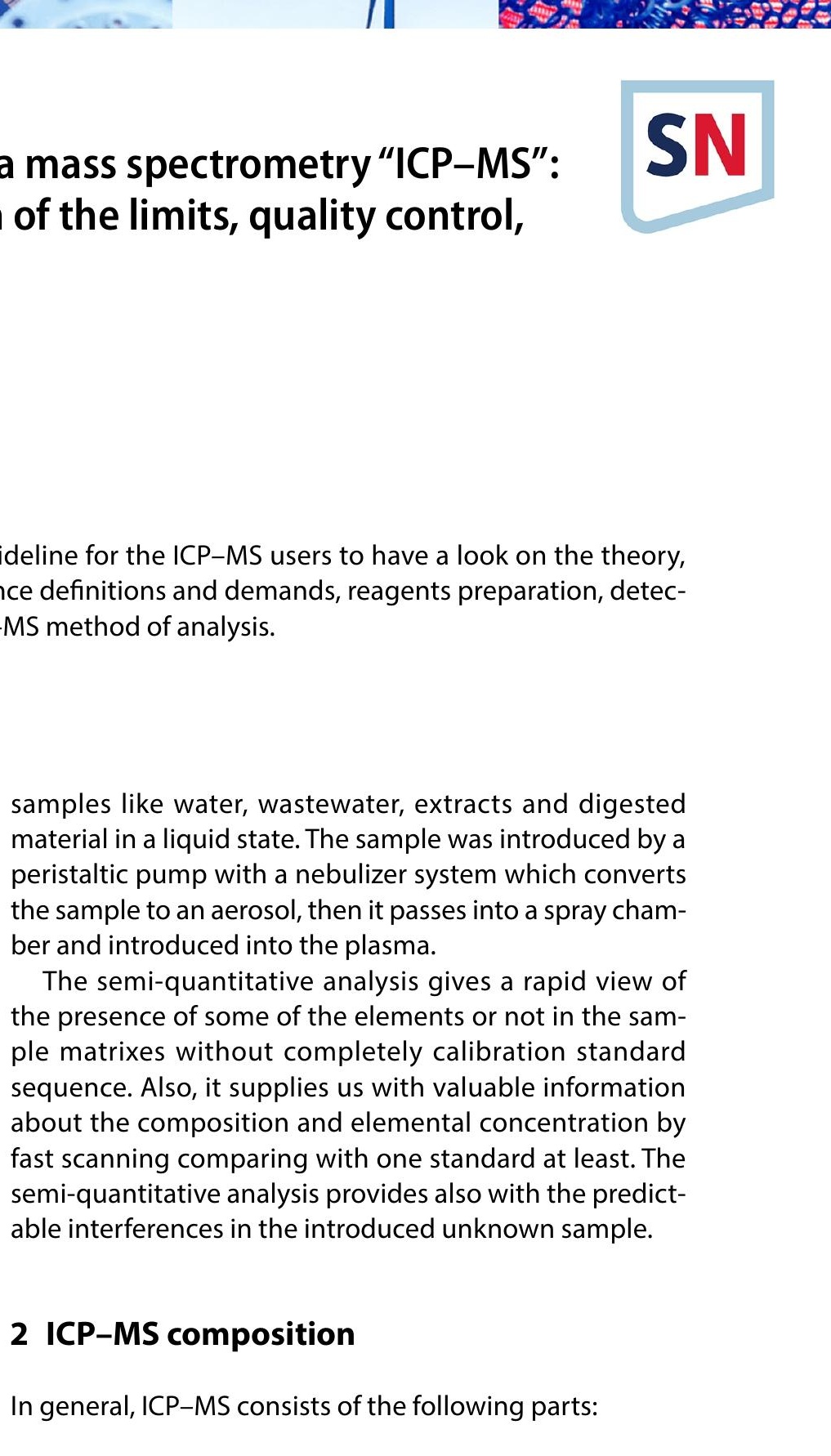

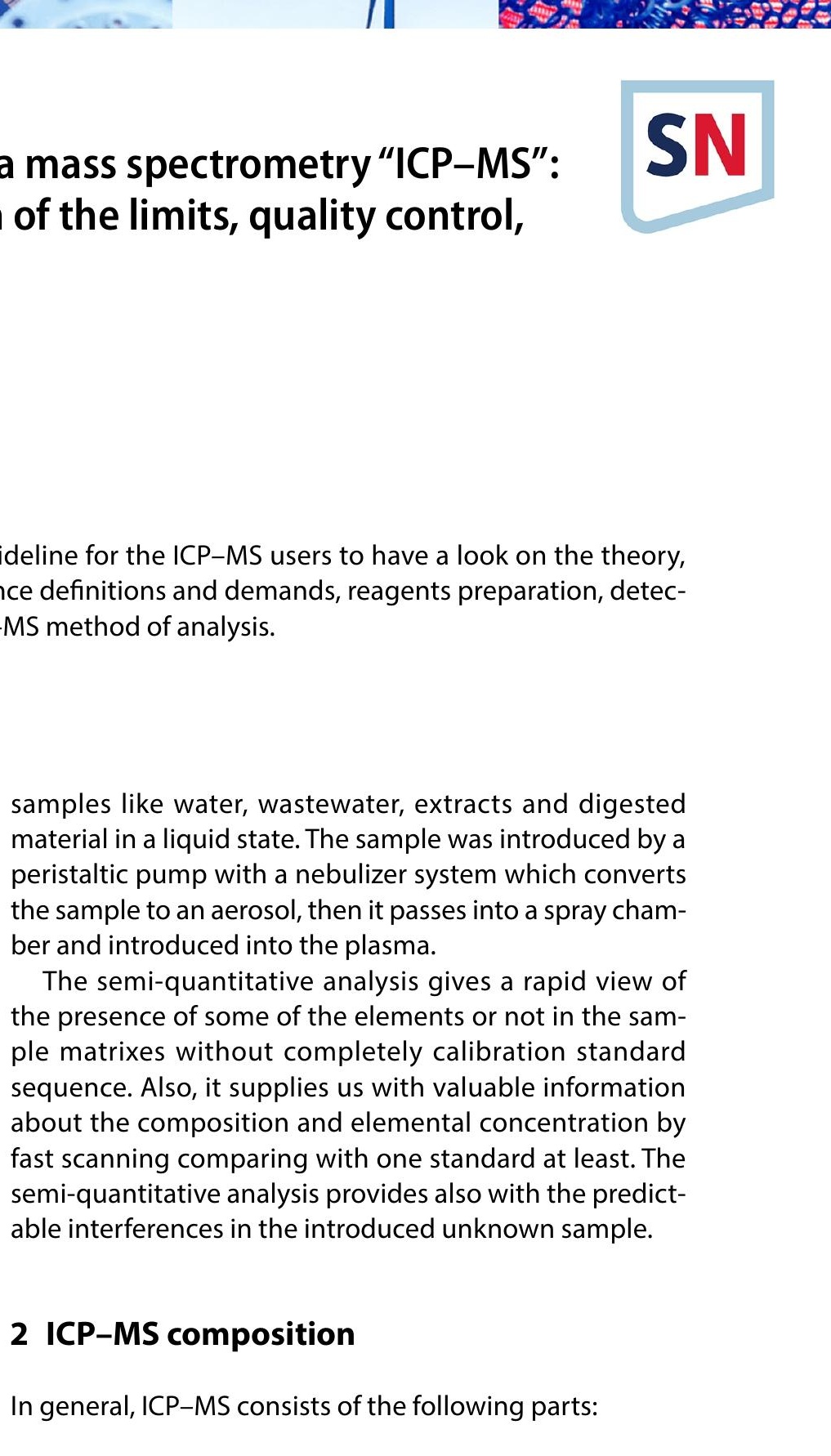

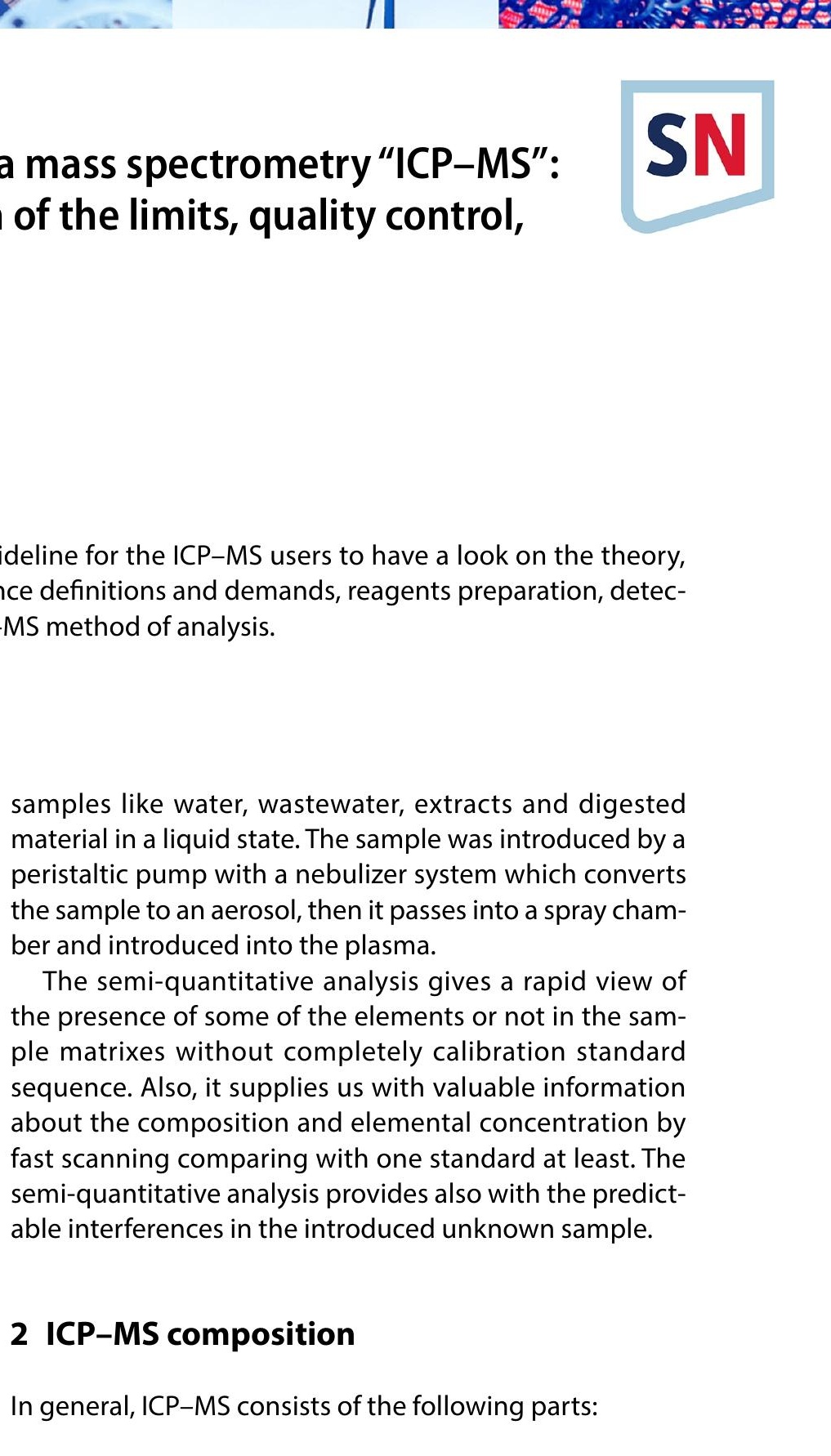

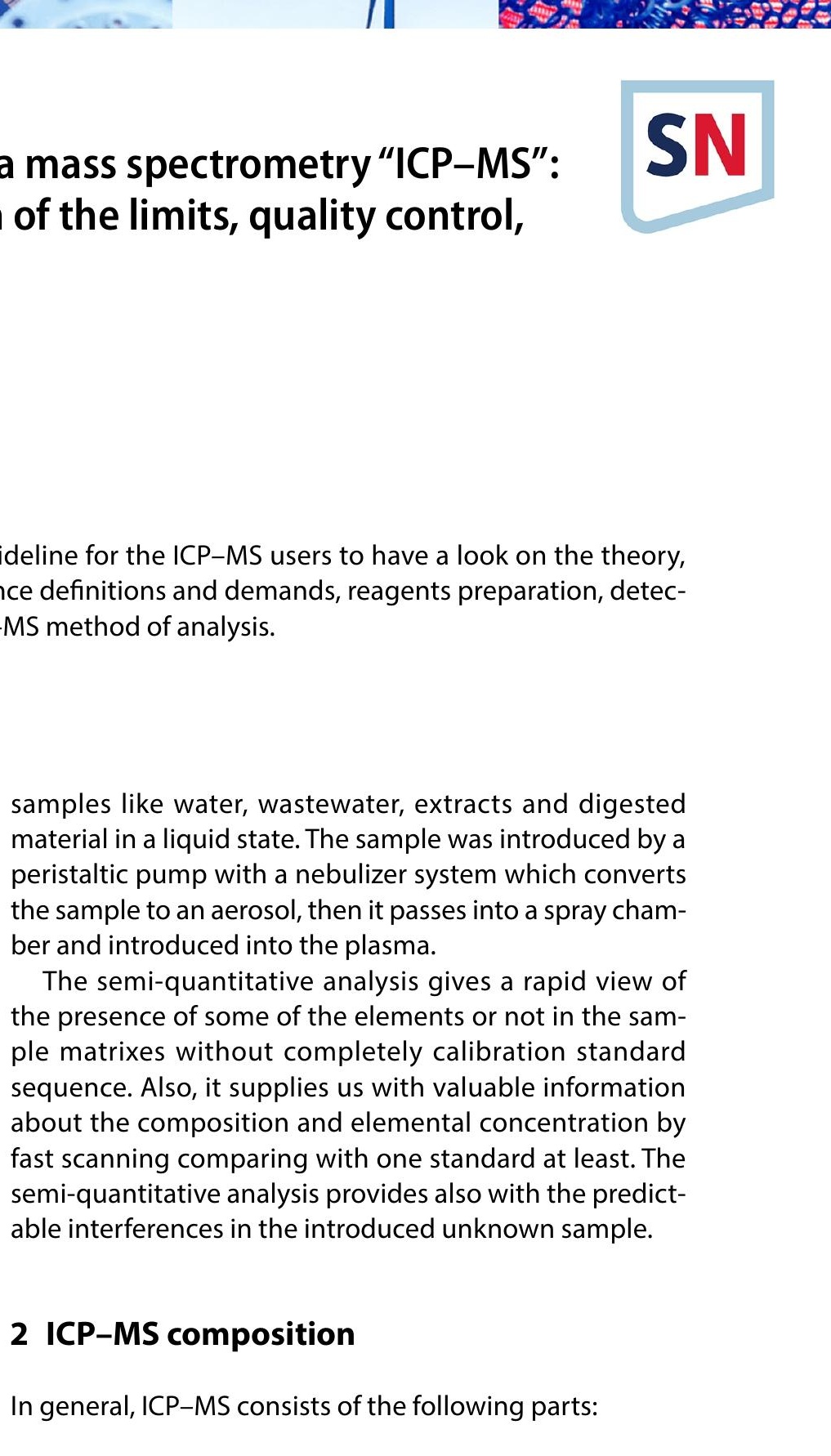

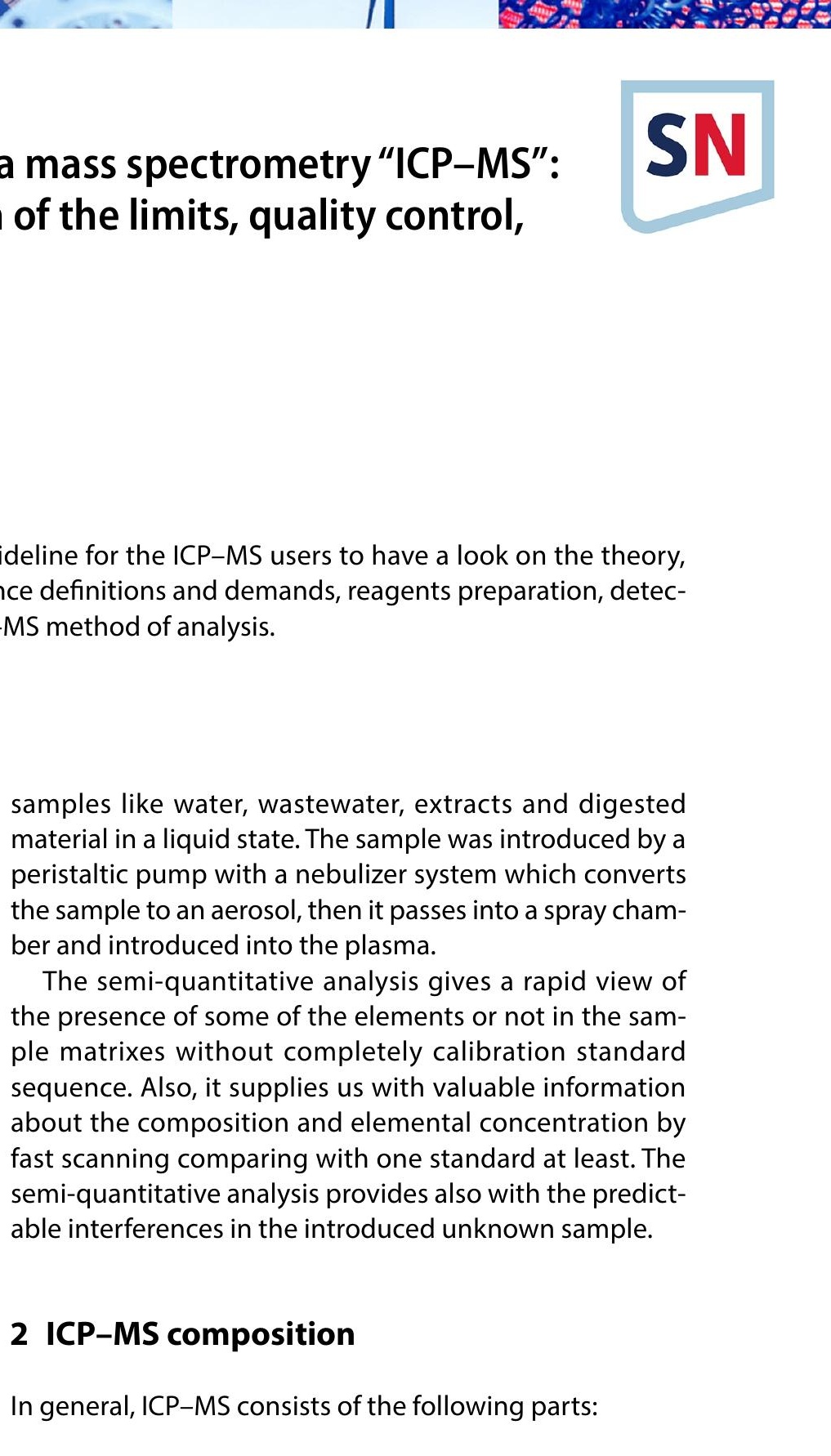

MasS Spectrometry "ICP-MS":
of the limits, quality Control,
ICline for the ICP-MS users to have a look on the theory,
MS method of analysis.
In general, ICP-MS consists of the following parts:
the presence of some of the elements or not in the sam-
ple matrixes without completely calibration standard
sequence. Also, it supplies us with valuable information
about the composition and elemental concentration by
fast scanning comparing with one standard at least. The
semi-quantitative analysis provides also with the predict-
able interferences in the introduced unknown sample.
samples like water, wastewater, extracts and digested
material in a liquid state. The sample was introduced by a
peristaltic pump with a nebulizer system which converts
the sample to an aerosol, then it passes into a spray cham-
ber and introduced into the plasma.
The semi-quantitative analysis gives a rapid view of

masS Spectrometry "ICP-MS":
of the limits, quality Control,
deline for the ICP-MS users to have a look on the theory,
ce definitions and demands, reagents preparation, detec-
MS method of analysis.
In general, ICP-MS consists of the following parts:
the presence of some of the elements or not in the sam-
ple matrixes without completely calibration standard
sequence. Also, it supplies us with valuable information
about the composition and elemental concentration by
fast scanning comparing with one standard at least. The
semi-quantitative analysis provides also with the predict-
able interferences in the introduced unknown sample.
samples like water, wastewater, extracts and digested
material in a liquid state. The sample was introduced by a
peristaltic pump with a nebulizer system which converts
the sample to an aerosol, then it passes into a spray cham-
ber and introduced into the plasma.

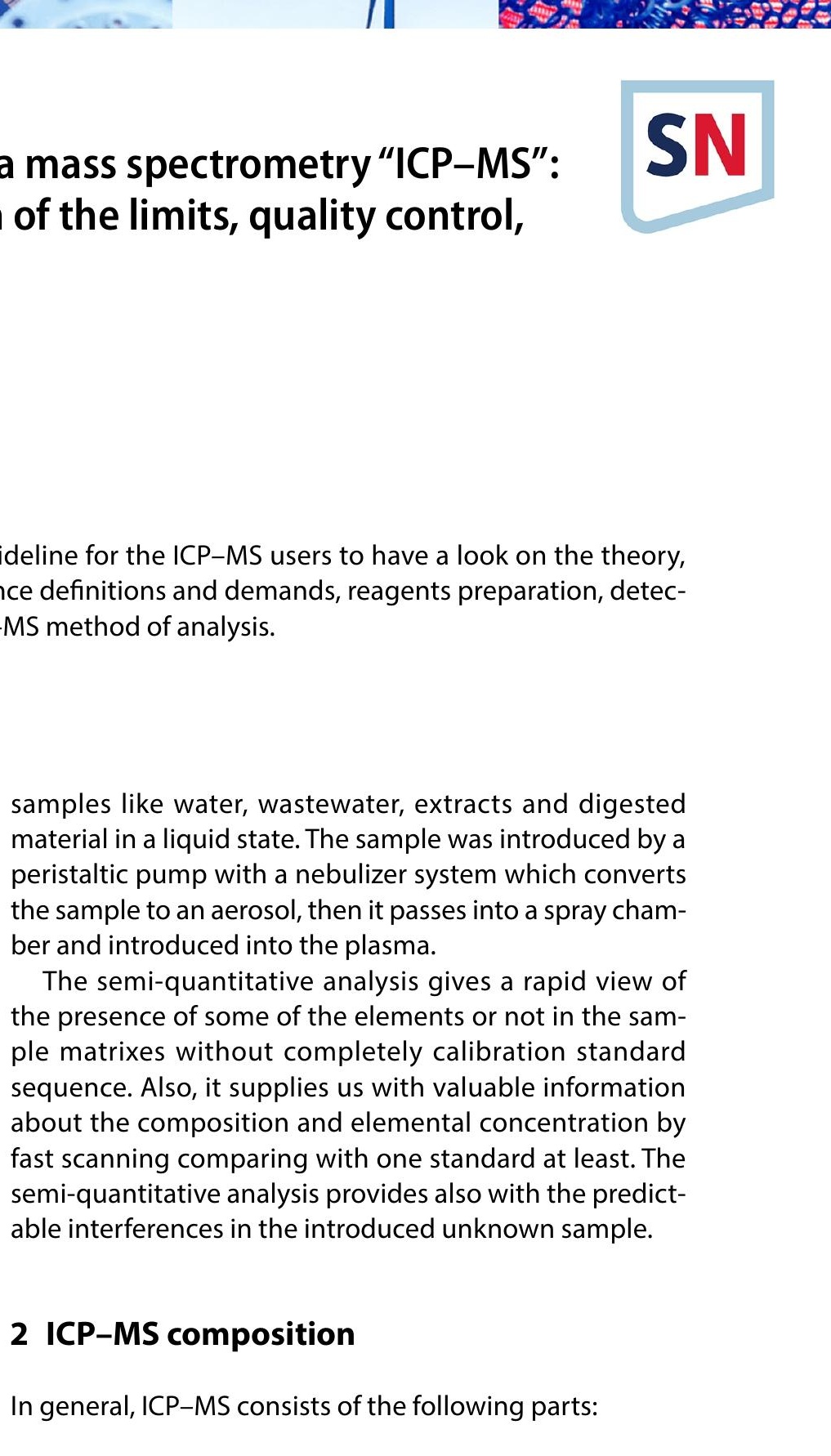

1. Introduction system of the sample which consists of nebulizer and spray chamber

2. ICP-torch and RF coil

3. Vacuum-interface system

Mostafa F. Al-Hakkani, mostafa.f@scinv.au.edu.eg| ${ }^{1}$ Chemistry Department, Faculty of Science, New Valley University, Al-Kharja 72511, Egypt.

SN Applied Sciences (2019) 1:791 | https://doi.org/10.1007/s42452-019-0825-5 


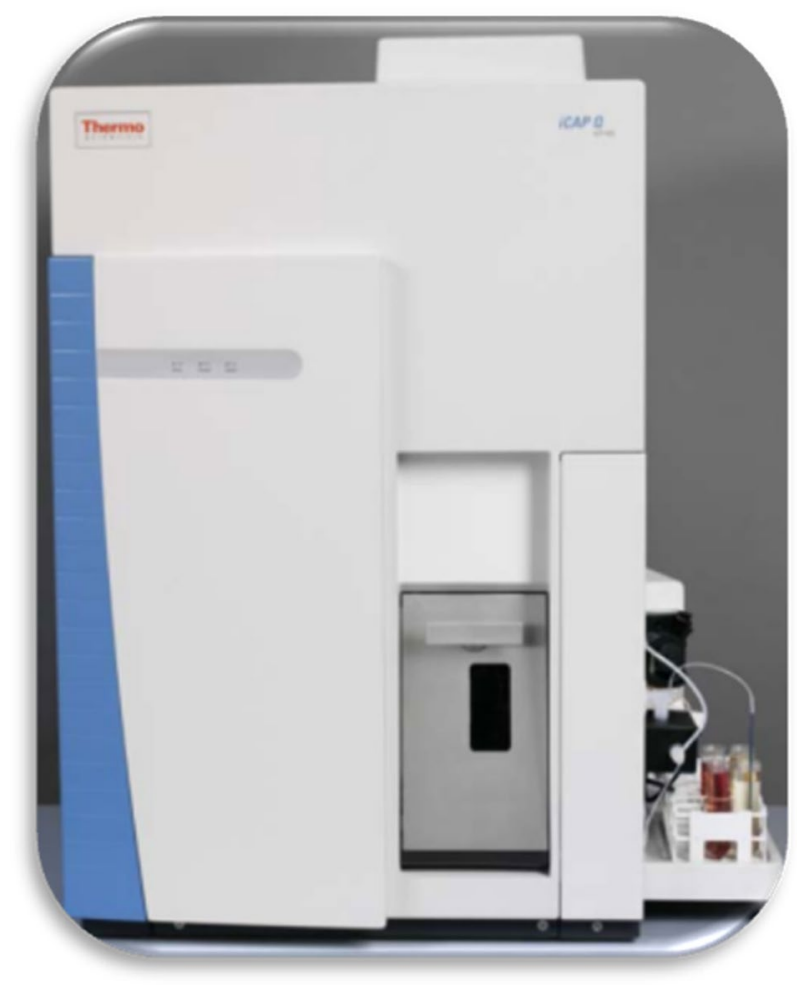

Fig. 1 Thermo ICP-MS model iCAP-RQ front view

4. Interference removal system as Collision/reaction cell "CCT or DRC"

5. Ion optics which work to focus the ions beam by separating the neutral species and photons
6. Mass spectrometer filtration system for sorting the ions according to their mass/charge ratio " $\mathrm{m} / \mathrm{z}$ "

7. Detector and data controlling system.

Nebulizer function summarized into sample introduction to the spray chamber in fine droplets through a peristaltic pump, see Fig. 3 for sample diagram.

Spray Chamber has two main functions:

A. Filter large droplets from the aerosol coming out of the nebulizer: The produced aerosol by nebulizer which entering the torch must be limited to minuscule sized droplets $(\sim 10 \mu \mathrm{m})$ or either the plasma will be interrupted or the torch will be extinguished.

B. Smooth out any "pulses". often due to the pumping of the solution.

- For most systems, only about $1-5 \%$ of the sample is converted into the requisite droplet range.

The rest goes to drain-waste.

- Spray chamber component material can be an important consideration. Need to be corrosion resistant materials to allow the introduction of matrices containing such as hydrofluoric acid.

Plasma is "partially ionized gas-an electrical conducting gaseous mixture" a mixture of a positive charge of argon ions and electrons which generated through a series of concentric quartz tubes known as the ICP-torch as in Fig. 4.
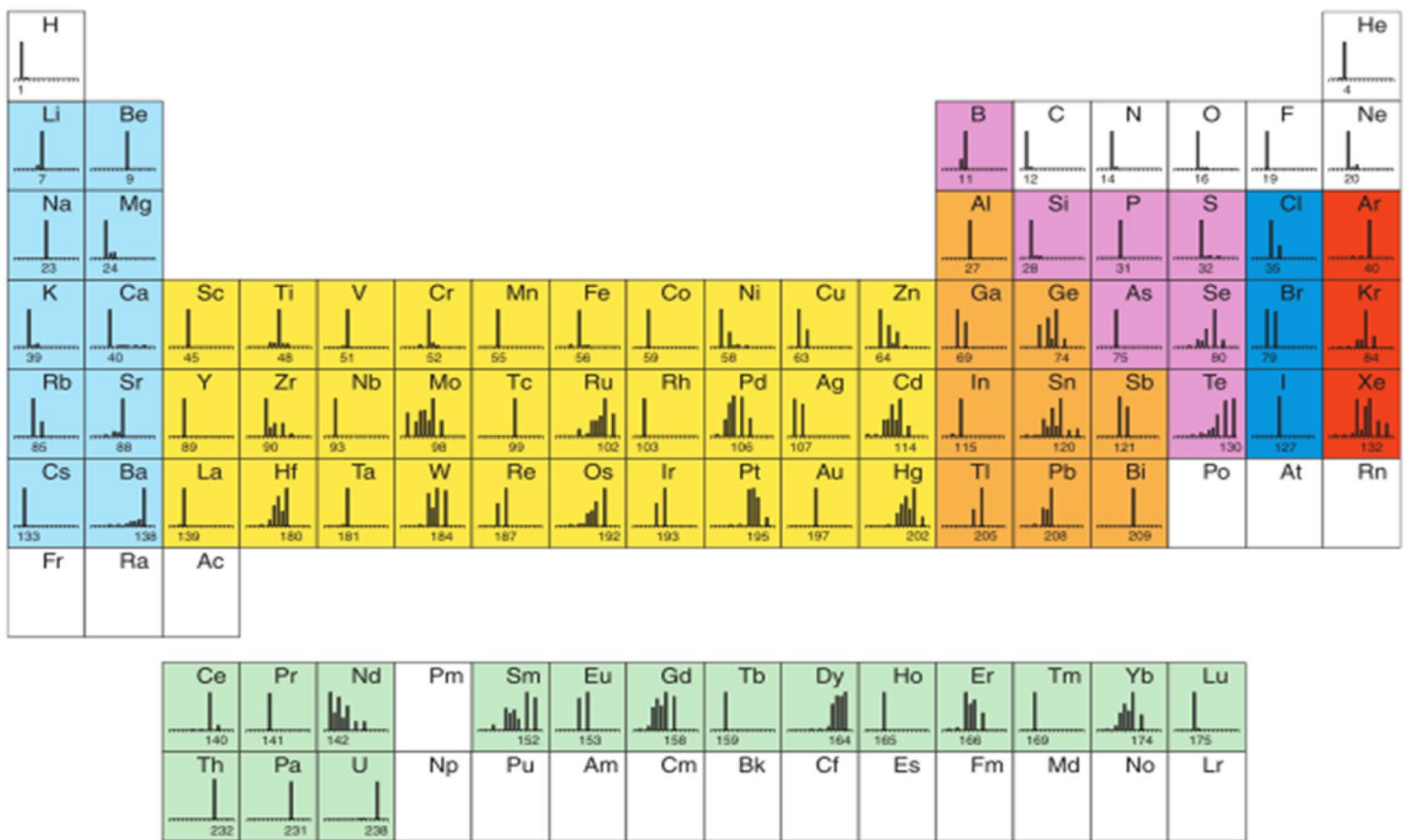

Fig. 2 Elements can be determined by ICP-MS 


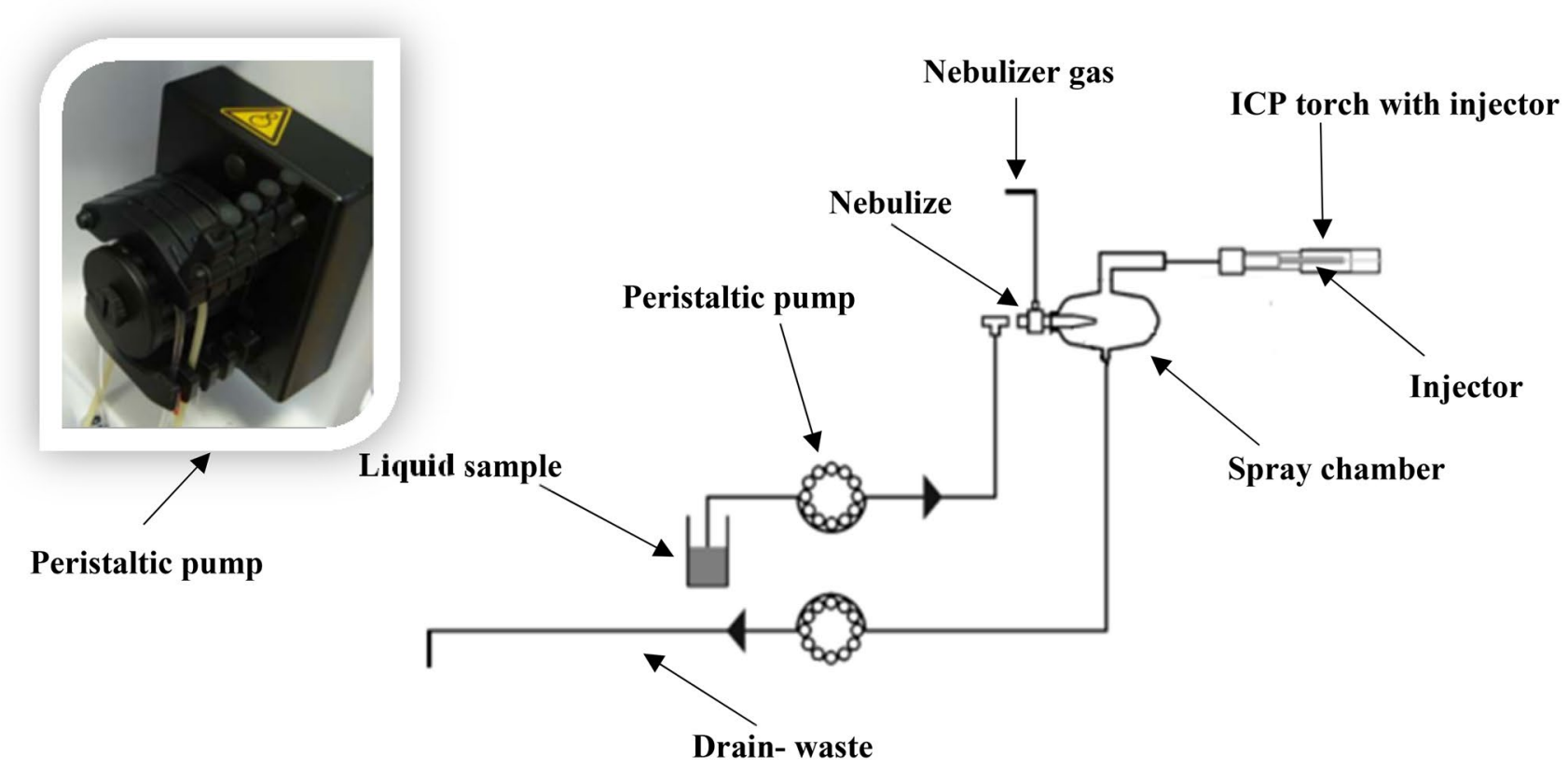

Fig. 3 Sample flow diagram

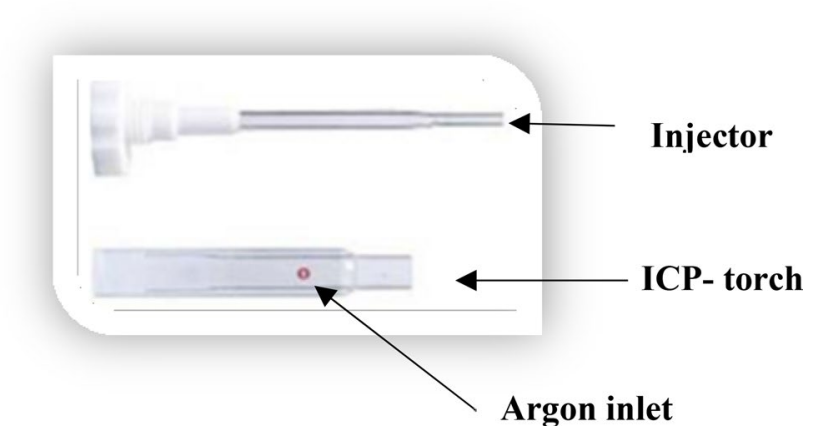

Fig. 4 ICP-torch and injector

It located in the center of a copper RF coil which generates a temperature of about $6000-10,000 \mathrm{~K}$ [1].

The collisions between argon gas and the accelerated electrons induce the high-temperature plasma to generate. After entrance the sample aerosol from spray chamber, instantly it was decomposed in the plasma atmosphere to give analyte atoms which subsequently are ionized and lose their electrons and produce a single positive ion of the sample constituents. Most elements ionize very efficiently $(>90)$ in the hot plasma [2].

The interface section of the instrument serves to allow the ICP and MS portions to be coupled using deferential pumping at vacuum interface system. There is a watercooled cone with a small orifice allows to the generated ions to extracted from the plasma atmospheric pressure (760 torr) into a high vacuum low-pressure region (typically $10^{-4}-10^{-5}$ torr) to the following stage in mass spectrometer sector. The analyte ions are extracted through a pair of slots, its diameter about $1 \mathrm{~mm}$, known as the sampling cone and the skimmer cone, see Fig. 5. Through a series of lenses "ion optics"; the analyte ions are focused into a quadrupole mass analyzer.

The produced elemental ions in the plasma Fig. 6 must be moved from the high temperature of plasma $7000 \mathrm{~K}$ to about $300 \mathrm{~K}$ at room temperature and also from atmospheric pressure to high vacuum.

Fig. 5 Cone tool and shaps

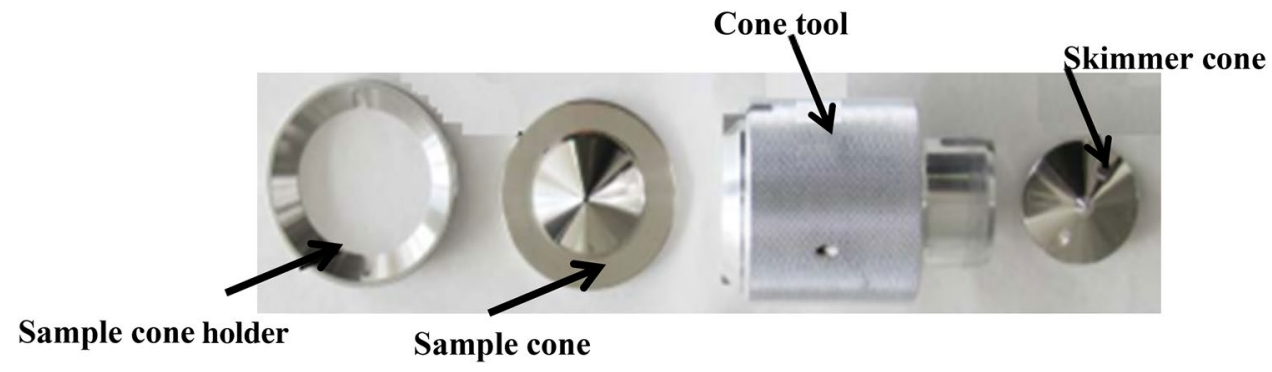




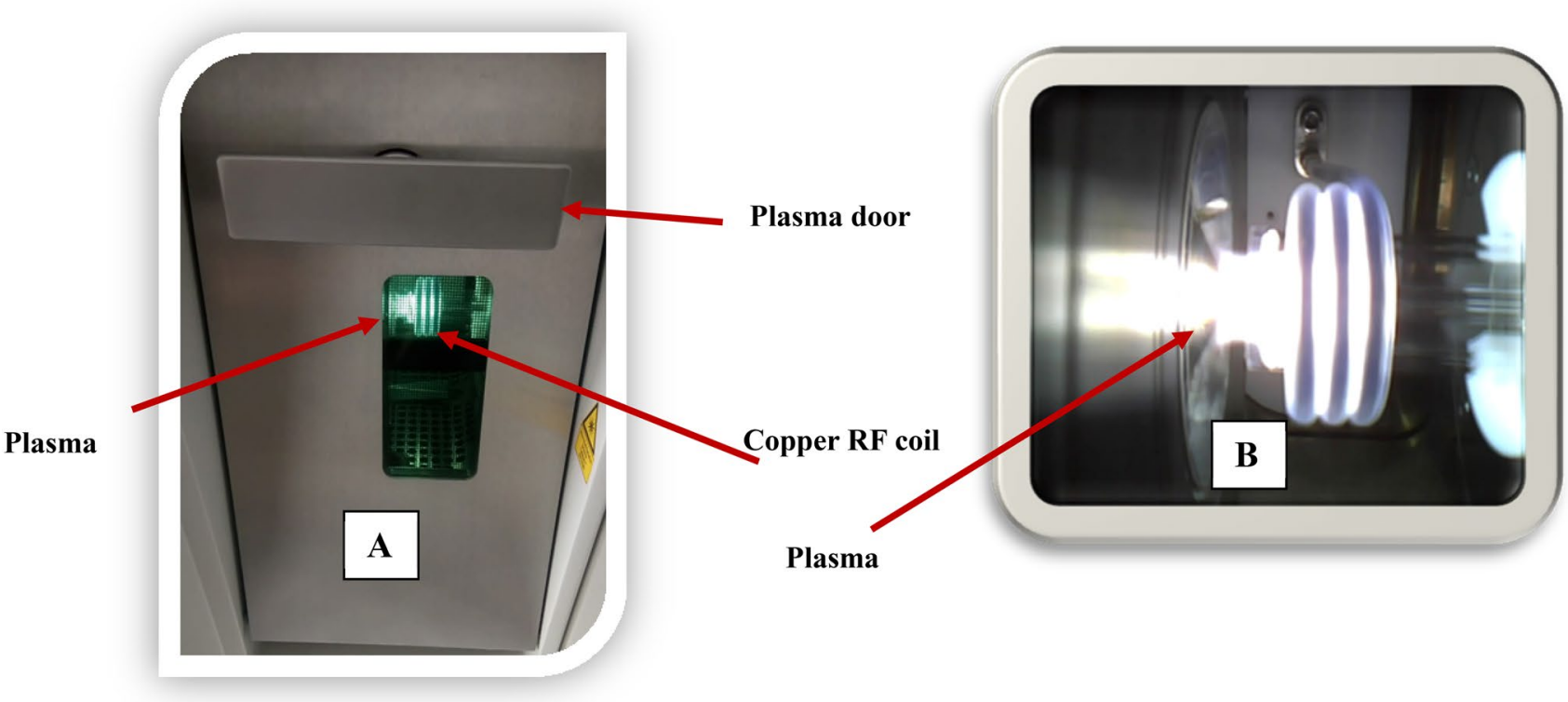

Fig. 6 Plasma ignition $(\mathbf{a}, \mathbf{b})$

To realize this action step, the ions should be extracted through a number of vents. Not only ions are produced in plasma but also photons are formed, the later passes through the vents. Photons are not discarded by vacuum [1]. So, it is the main reason in the presence of high noises when they reach the detector. To minimize these noises, a small metal plate placed in the center of the ion beam to reflect the photons away from the detector. On the contrary; the positive ions are not stopped by photon stop plate because the positive charges are focused around the cylinder lens [2].

Typically, either a quadrupole (with or without CCT or DRC) or magnetic sector (high-resolution) mass spectrometer is used. Finally, the ions are separated accouraging to the ratio of mass per charge $(\mathrm{m} / \mathrm{z})$ and the ions are detected with an electron multiplier, subsequently; the data of all masses are collected and stored through a computer interface.

Using ICP-MS can measure all types of the matter samples (Solid [3], liquid, and gas [4]) using laser ablation technique for solids, vaporization by nebulizer for liquids, and on the other hand, the gaseous samples are introduced directly.

\subsection{Obtaining a stable plasma}

Allow continual nebulization of a warm-up solution for about 30 min "or depending on the instrument's manufacturer recommendation" prior to optimizing the instrument.
This procedure allows the components in the interface region of the ICP-MS to become conditioned to the matrix in the test solutions.

\section{ICP-MS interferences types and their treatments}

- Isobars

Isobars are isotopes for different elements that form ions with the same nominal atomic mass units per charge number $(\mathrm{m} / \mathrm{z})$ as in Table 1 . It cannot be resolved by a quadrupole or high-resolution mass spectrometer. These interferences can be resolved by ICP-MS operating software which includes all types of isobaric interferences and will perform the necessary calculations automatically. So, the chemist should be verified that all elemental and molecular correction equations used in this method are correct and appropriate for the mass spectrometer used and the sample matrix [5].

Table 1 Isotopes used for correction some of the isobaric interferences

\begin{tabular}{ll}
\hline Isotopes used for correction & Interference occurs between \\
\hline${ }^{83} \mathrm{Kr}$ & ${ }^{82} \mathrm{Kr},{ }^{82} \mathrm{Se}$ \\
${ }^{99} \mathrm{Ru}$ & ${ }^{98} \mathrm{Ru},{ }^{98} \mathrm{Mo}$ \\
${ }^{118} \mathrm{Sn}$ & ${ }^{114} \mathrm{Sn},{ }^{114} \mathrm{Cd} /{ }^{115} \mathrm{Sn},{ }^{115} \mathrm{In}$ \\
${ }^{125} \mathrm{Te}$ & ${ }^{123} \mathrm{Te},{ }^{123} \mathrm{Sb}$ \\
$\mathrm{ArCl}$ at mass 77 & $\mathrm{Chloride}$ \\
\hline
\end{tabular}


- Abundance sensitivity

Abundance sensitivity is the possibility that the low and high "wings" of an abundant mass peak will contribute to or obscure adjacent masses. It resolved by adjusting the mass spectrometer resolution and quadrupole pole bias to minimize these interferences [5].

\section{- Polyatomics}

Polyatomic is (molecular) ion interferences caused by ions with more than one atom that have the same nominal $\mathrm{m} / \mathrm{z}$ ratio as the isotope of interest. Most of the common molecular ion interferences have been identified. Because of the severity of chloride ion interference on important analytes, particularly vanadium and arsenic, hydrochloric acid is not recommended for use in ICP-MS sample preparation. Because of most environmental samples contain some chloride ion, the chemist must use chloride-correction equations for affected masses. Collision cell technology "CCT" and dynamic reaction cell "DRC" effectively reduce most the polyatomic species to analytically negligible levels in quadrupole-based ICP-MS systems or using kinetic energy discrimination (KED) mode [6].

KED mode: It used for detection of $\mathrm{Co}, \mathrm{Ni}, \mathrm{Cu}$ and $\mathrm{Zn}$, As and Se which are subjected to the larger crosssectional polyatomic interferences.

A high-resolution ICP-MS resolves many but not all interferences caused by polyatomic ions. Polyatomic interferences are strongly influenced by instrument design and plasma operating conditions; it can be reduced by carefully adjusting nebulizer gas flow; about (1.5-1.8 $\mathrm{ml} / \mathrm{min})$, RF power adjustment (500$800 \mathrm{~W}$ ). and other instrument operating parameters [5].

- Doubly-charged

Some elements (e.g., strontium and barium) form significant levels of $\mathrm{M}^{+2}$ ions under normal plasma conditions. The $\mathrm{M}^{+2}$ ions occur in the mass spectrum at $\mathrm{M} / 2$ and, in the case of $\mathrm{Ba}$ and $\mathrm{Sr}$, will interfere with some isotopes of zinc and calcium, respectively [5].

- Physical interferences

These include differences in viscosity, surface tension, and dissolved solids between samples and calibration standards. To minimize these effects, analytical samples should not contain more than $0.1 \%$ of dissolved solids. Dilute water and wastewater samples which have higher dissolved solids levels before analyzing them. Use internal standards to correct for physical interferences [5].

- Memory interferences

These occur when analytes from a previous sample or standard are measured in the current sample and make carry-over in the measured value. Use a long enough rinse (flushing) between samples to minimize such interferences. Continues appearing of memory interferences may indicate problems in the sample introduction system. Complicated memory interferences may require the chemist to disassemble and clean the entire sample introduction system, including the plasma torch, the sampler and skimmer cones [5].

- Ionization interferences

These results when moderate (0.1-1\%) amounts of a matrix ion change the analyte signal. This effect, which usually reduces the analyte signal, also is known as suppression. Correct for suppression by using internal standardization techniques [5].

It should be noted that several elements including $S$, $\mathrm{Se}, \mathrm{B}, \mathrm{Si}, \mathrm{P}, \mathrm{Br}, \mathrm{I}, \mathrm{K}$, and $\mathrm{Ca}$ have high detection limits via ICP-MS. In the case of I and $B r$, this is due to the fact that very few positive ions are formed in the ICP plasma for these elements. For elements such as $\mathrm{S}, \mathrm{Se}, \mathrm{P}, \mathrm{K}$, and $\mathrm{Ca}$, isobaric and molecular interferences from either the sample matrix or plasma species interfere with the primary isotope. This means that less abundant isotopes with less interference (if available) must be used for determination of these elements, which will degrade detection capabilities for these elements.

\section{ICP-MS advantages over other elemental analysis techniques such as atomic absorption spectroscopy (AAS), ICP-optical emission spectrometry (ICP-OES) and ICP-atomic emission spectroscopy (ICP-AES)}

- Detection limits for most elements equal to or better than those obtained by Graphite Furnace Atomic Absorption Spectroscopy (GFAAS).

- Fast analysis times (all elements at once).

- Handling both simple and complex matrices with a minimum of matrix interferences due to the hightemperature of the ICP source.

- Superior detection capability to ICP-AES with the same sample throughput.

- The ability to obtain isotopic information.

- An ICP-MS can be combined a high-temperature ICP (Inductively Coupled Plasma) source with a mass spectrometer.

- Specialized sample introduction systems can be coupled to an ICP-MS, including spark- or laser-ablation systems, hydride generators, and chromatography systems (GC, IC, HPLC, and UPLC systems). In these cases, sample preparation protocols will vary depending on the sample introduction system being used. 


\subsection{Some of the latest introduced researches of ICP-MS at the different fields}

- Scientific researches [7-16].

- Clinical analysis; as urine [17-19], blood [20-24].

- Pharmaceutical analysis; as active pharmaceutical ingredient raw material [25] and drug finished products [26-28].

- Food analysis [29-32].

- Environmental analysis [33, 34]; as water [12, 35, 36], wastewater [37, 38].

- Fertilizers analysis [39-41].

\subsection{Some of quality control and quality assurance practices terminology}

Accuracy An estimate of how close a measured value is to the true value; includes expressions for bias and precision.

Bias Aconsistent deviation of measured values from the true value, caused by systematic errors in a procedure.

Precision (usually expressed as standard deviation) Ameasure of the degree of agreement among replicate analyses of a sample.

Analyte The element, compound, or component being analyzed.

Fortification "Spike" The addition of a known quantity of analyte to a sample or blank to increase the analyte concentration, usually for the purpose of comparing to test result on the unfortified sample and estimating percent recovery or matrix effects on the test to assess accuracy.

Internal standard Apure compound added to a sample extract just before instrumental analysis to permit correction for inefficiencies.

Laboratory control standard Astandard usually certified by an outside agency that is used to measure the bias in a procedure. For certain constituents and matrices, use National Institute of Standards and Technology (NIST) or other national or international traceable sources (Standard Reference Materials), when available.

Reference materials Use externally prepared reference material, preferably from National Institute of Standards and Technology (NIST) 1643 series or equivalent.

Quality assurance Adefinitive plan for laboratory operations that specifies the measures used to produce data with known precision and bias.
Quality control Aset of measures used during an analytical method to ensure that the process is within specified control parameters.

Batch Agroup of samples which behave similarly with respect to the sampling or the testing procedures being employed and which are processed as a unit. For QC purposes, if the number of samples in a group is greater than 20 , then each group of 20 samples or less will all be handled as a separate batch.

Dissolved metals Those elements which pass through a $0.45-\mu \mathrm{m}$ membrane filter (sample is acidified after filtration).

Tuning solution This is a multi-element solution containing analytes which are representative of the entire mass range capable of being scanned by the instrument. It is used to optimize the sensitivity of the instrument and to verify the mass resolution.

Sensitivity It is the slope of the analytical curve.

Ruggedness (inter-precision) Ruggedness of an analytical method is the degree of reproducibility of the test results obtained by the analysis of the same samples under a variety of conditions as a major change such as different analysts, different days, etc. [42, 43].

Type lerror (also called a error) It is the probability of determining that a constituent is present when it actually is absent.

Type Il error (also called $\beta$ error) It is the probability of not detecting a constituent that actually is present.

\subsection{Reagents and handling procedures}

1. Water The used water in preparation of blanks, standards, and samples should be; Reversed osmosis (RO) water or deionized (DI) water and metal-free water at least with minimum specs as in Table 2.

2. Acids Use ultra-high-purity grade (or equivalent) acids to prepare standards and process samples. Use extreme care when handling acids in the laboratory to avoid contaminating them with trace levels of metals.

1. Nitric acid $\left(\mathrm{HNO}_{3}\right)$, concentrated (specific gravity 1.41).

2. Nitric acid, 1:1: Add $500 \mathrm{~mL}$ conc $\mathrm{HNO}_{3}$ to $500 \mathrm{~mL}$ reagent water.

3. Nitric acid, (v/v) 2\%: Add $20 \mathrm{~mL}$ conc $\mathrm{HNO}_{3}$ to $100 \mathrm{~mL}$ reagent water; dilute to $1000 \mathrm{~mL}$. 
Table 2 Specs of water quality using in ICP-MS analysis

\begin{tabular}{llll}
\hline Quality parameter & High & Medium & Low \\
\hline Resistivity, megohm-cm at $25^{\circ} \mathrm{C}$ & $>10$ & $>1$ & $>0.1$ \\
Conductivity, $\mu \mathrm{S} / \mathrm{cm}$ at $25^{\circ} \mathrm{C}$ & $<0.1$ & $<1$ & $<10$ \\
\hline
\end{tabular}

4. Nitric acid, (v/v) 1\%: Add $10 \mathrm{~mL}$ conc $\mathrm{HNO}_{3}$ to $100 \mathrm{~mL}$ reagent water; dilute to $1000 \mathrm{~mL}$.

3. Argon gas Use a pre-purified grade of argon at least purity $(99.999 \%)$ which is usually necessary because technical argon often contains significant levels of impurities (e.g., carbon and krypton). ${ }^{82} \mathrm{Kr}$ interferes with the determination of ${ }^{82} \mathrm{Se}$. Monitor ${ }^{83} \mathrm{Kr}$ at all times.

4. Helium gas Helium at least purity (99.999\%) used as an ion source "auxiliary gas" for plasma to exclude some of the interferences formations as ArO. It has great benefits; where it produces plasma to induce the ionization of some elements which have a high ionization potential efficiently more than the Argon gas only and also. The mixture of Argon and Helium show an improvement in detection limits for several elements [44].

5. Airborne contaminants

It is preferable to work in clean laboratory facilities such as laminar-flow clean-air to avoid final dust contamination.

6. Glassware

All used glassware must be class $\mathrm{A}$.

7. Cleaning procedures

(A) Between sample transfers:

1. Rinse with 1:1 nitric acid or chromic acid.

2. Rinse with RO/DI water.

3. Rinse with the sample.

(B) After use:

1. Wash with detergent by hand or in pipet washer, as appropriate.

2. Rinse with tap water.

3. Rinse with 1:1 nitric acid or chromic acid.

4. Rinse with RO/DI water at least three times.

5. Place in rack and cover.

\subsection{Preparation, working and test instruction procedures}

1. System suitability/Instrument optimization/Tuning solution
Table 3 Perkin Elmer Elan 6000 ICP-MS tuning solution [1]

\begin{tabular}{ll}
\hline Element(s) in $2 \% \mathrm{HNO}_{3}$ & Function \\
\hline $\mathrm{Be}, \mathrm{Cd}, \mathrm{Co}, \mathrm{Cu}, \mathrm{Ge}, \mathrm{In}, \mathrm{Rh}, \mathrm{Sc}, \mathrm{Tb}$ & Sensitivity and stability evaluation \\
and $\mathrm{Tl}$ & \\
$\mathrm{Ba}$ & Doubly-charged evaluation \\
$\mathrm{Cs}$ & Oxide evaluation \\
$\mathrm{Mg}$ and $\mathrm{Pb}$ & Mass calibration check
\end{tabular}

Preparation and criteria for this solution, depending on the instrument manufacturer's recommendations, for example, Table 3.

2. Reagent Blank (RB)/Method Blank (MB)/Initial Calibration Blank (ICB)/Calibration Verification Blank (CVB)/ Continuing Calibration Blank (CCB).

Definition It is a portion of reagent water treated exactly like a sample, including exposure to all glassware, procedures, and reagents. It is used to assess whether analytes or interferences are present in the analytical process or system. The reagent blank is used to determine whether and how much reagents and the preparative analytical steps contribute to measurement uncertainty.

\section{Acceptance criteria [45]}

If reagent blank is $\angle M D L$, then no qualification is required.

If reagent blank is $\geq 1 / 2 \mathrm{LOQ}$ and $<\mathrm{LOQ}$ and sample results are $>L O Q$, then qualify results to indicate that analyte was detected in the reagent blank.

If reagent blank is $>L O Q$, then further corrective action and qualification is required.

Note For dissolved samples, take reagent water through same filtration and preservation processes used for samples. For samples requiring digestion, process reagent water with the same digestion techniques as samples.

Frequency One each batch at least, favorable analyze a blank after each calibration standard and before analyzing samples.

\section{Range (limit of linearity)}

In briefly the range is the value in-between the minimum and maximum concentration in the calibration curve. Initially, we can use the $L O Q$ as the minimum point in establishing the limits of linearity. The maximum concentration can be measured within $10 \%$ of its true value 
based on the calibration Curve" this is the limit of linearity". All samples whose concentrations are above the limit of linearity must be diluted.

\section{Internal standard solution}

Definition "Germanium, indium, lithium, scandium, and thorium are suggested as internal standards" was added with enough with the same volume to all samples, standards, and quality control (QC) samples to give a suitable counts/second (cps) signal and stability $(100,000$ $300,000 \mathrm{cps}$ for most internal standards).

Other internal standards, such as bismuth, holmium, rhodium, terbium, and yttrium, may also be used in this method. Ensure that the internal standard mix used is stable and that there are no undesired interactions among elements.

Preparation and determination All new sample matrices should be screened for internal standard elements before analysis.

Analyzing a few representative samples for internal standards should be sufficient. Analyze samples "as received" or "as digested" (before adding internal standard), then add internal standard mix and re-analyze.

\section{Acceptance criteria}

- Generally, $70-125 \%$ of response in calibration blank with known addition.

- Ensure that there are no significant changes in its behavior from sample to sample. If a significant difference, i.e., greater than $25 \%$, in the response obtained from a procedural blank and that from a sample, this should be taken as an indication of matrix effect or interference/contamination and would require further investigation.

- Monitor counts at the internal standard masses. If the "received" or "digested" samples show appreciable detector counts ( $10 \%$ or higher of samples with added internal standard), dilute sample or use another internal standard.

- If the response of a sample containing the internal standard is not within $70-125 \%$ of the response for a calibration blank with the internal standard, either dilute the sample before analysis or use another internal standard. During actual analysis, monitor internal standard masses and note all internal standard recoveries that are more than $125 \%$ of the internal standard response in the calibration blank. Interpret results for these samples with caution [5].
5. Detection limits determination

Instrument detection level (IDL) and method detection level (MDL) are often incorrectly used interchangeably. The detection level is the smallest amount of a substance that can be detected above the noise in a procedure and within a stated confidence level. Currently, there are several types of detection levels [46]:

Instrument detection level "IDL", Method detection level "MDL", Lower level of detection "LLD" and Level of quantitation "LOQ"

The relationship among them is approximately

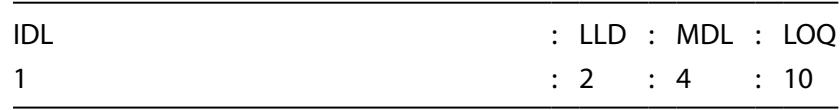

Chemists may use the IDL or LLD as a guide for determining the MDL.

Any operation of the analytical instrument usually produces a signal even when no sample is present (electronic noise) or when a blank is being analyzed (e.g., molecular noise). Because any QA program requires frequent analysis of blanks, the mean and standard deviation of this background signal become well known.

\subsection{Instrument Detection Level (IDL)}

Definition It is the constituent concentration that produces a signal greater than three standard deviations of the mean noise level. It can be determined by injection of a standard into the instrument to produce a signal that is five times the signal-to-noise ratio.

Preparation and determination The IDL can be determined as 1.645 times of the STDEV of blank analyses (where STDEV is the estimate of standard deviation for $\mathrm{n}$ blanks, preferable $n=7-10$ ).

The IDL is useful for estimating the constituent concentration (amount) in an extract needed to produce a signal to permit calculating an estimated MDL [46]. The IDL should always be less than the method detection limit. For many analytes, the instrument detection limits (IDLs) are between 1 and $100 \mathrm{ng} / \mathrm{L}$ "ppt".

Frequency Repeated annually or whenever the instrument configuration changes or major maintenance occurs, whichever happens first. 
5.2 The lower level of detection (LLD) also called detection level (DL) or level of detection (LOD)

Definition It is the amount of constituent that produces a detectable signal in each trial; about $99 \%$ of trials gives distinguished signal differs from the instrument signal. It is specific for matrix, method, and analyte.

\section{Preparation and determination}

1. $L O D$ is the constituent concentration in reagent water that produces a signal $\left(2 \times 1.645 \times \operatorname{STDEV}_{B}=3.290 \times \mathrm{S}\right.$ $\mathrm{TDEV}_{B}$ ) above the mean of blank analyses. This establishes both Types I and Type II errors at 5\% [46]. So, to reduce the probability of a Type II error to $5 \%$, we multiply STDEV in 3.290 .

$\mathrm{LOD}=3.29 \times \mathrm{STDEV}_{\mathrm{B}}$

2. LOD can be determined by multiple samples of a standard " $n$ samples" at near-zero concentrations (no more than five times the IDL). Then estimate the standard deviation "STDEV std" " of "n samples", then the LOD will be calculated as the following formula

$\mathrm{LOD}=3.29 \times \mathrm{STDEV}_{\text {std }}$

For example, if 20 determinations of a low-level standard yield a STDEV $=6 \mu \mathrm{g} / \mathrm{L}$, then the LOD is $3.29 \times 6-20 \mu \mathrm{g} / \mathrm{L}$.

3. It can be expressed also, by statistical relationship as LOD determination of chromatographic system $[42,43$, 47] as the following formula

$\mathrm{LOD}=3.3 \times \sigma / \mathrm{S}$

where $\sigma$ is the standard error; $S$ is a slope of the linearity calibration curve.

4. Another method for LOD determination can be used by Thermo Scientific [6] according to the following formula

$\mathrm{LOD}=3 \times \sigma_{\mathrm{B}} \times \mathrm{Std}_{\text {conc }} /\left(\mathrm{R}_{\text {conc }}-\mathrm{R}_{\mathrm{B}}\right)$

$\sigma_{B}$ is the standard deviation of the intensities of the multiple blank measurements; $R_{\text {conc }}$ is the mean signal for the standard (prepared at concentrations 1,5 and $10 \mathrm{ppb}$ in $2 \%$ Nitric acid); $\mathrm{R}_{\mathrm{B}}$ is the mean signal for the blank; Std $_{\text {conc }}$ is the concentration of the standard.

Note All solutions were prepared in freshly rinsed vials.

Frequency Repeated annually or whenever the instrument configuration changes or major maintenance occurs, whichever happens first.
5.3 Method detection level (MDL)

Definition It is the constituent concentration that, when processed through the entire method, produces a signal that has a $99 \%$ probability of being different from the blank. It must use a sample containing the interest constituent. The MDL differs from the LOD in that samples containing the constituent of interest are processed through the complete analytical method. But if we use the standard which contains the same interest constituent; in this case $L L D=L O D=M D L$ at the same number of replicates [46].

MDL is larger than LOD if the LOD calculated according to reagent water $=$ blank without using the standard spiking method.

Preparation and determination The starting point is selecting the concentration to use at five times the estimated true LOD. Start by adding the known amount of constituent to reagent water or sample matrix to achieve the desired concentration " $5 \times$ LOD". Ideally, prepare and analyze at least seven replicates of this solution over 3 days to ensure that the $\mathrm{MDL}_{\mathrm{s}}$ "standard $\mathrm{MDL}$ " determination is representative of routine measurements in the laboratory. The replicate measurements should be in the range of one to five times the estimated MDL" $5 \times$ LOD".

The $M D L_{s}$ will be larger than the LOD because typically seven replicates are used. Additionally, the $\mathrm{MDL}_{s}$ will vary with the matrix. If we use 7 replicates of the sample, the value of " $3.14 \times$ STDEV" must be above the blank result (where STDEV is the standard deviation of the seven replicates).

Ideally, estimated STDEV was expressed as pooled STDEV at 3 different sets at different days by the different chemist if more than one chemist performs the tests on the instrument.

If the calculated $\mathrm{MDL}_{s}$ is not within a factor of 10 from the known addition, repeat determinations at a more suitable concentration " $4 \times$ LOD or, $3 \times$ LOD and so on". If the spiked concentration $5 \mu \mathrm{g} / \mathrm{L}$. so, the $\mathrm{MDL}_{\mathrm{s}}$ must be less than $0.5 \mu \mathrm{g} / \mathrm{L}$ ". The $\mathrm{MDL}_{\mathrm{s}}$ typically will be higher than the IDL because of background levels "signal" of analytes introduced during sample preparation as in Table 4.

On the other hand, $M D L_{B}\left(M D L_{B}\right.$ based on method blanks) should be calculated using the following procedure.

A. If none of the method blanks give a numerical result (positive or negative), then $\mathrm{MDL}_{B}$ is not applicable, and $\mathrm{MDL}=\mathrm{MDL}_{\mathrm{s}}$. 
Table 4 Vanadium $\mathrm{MDL}_{\mathrm{s}}$ determination for one chemist for the first time

\begin{tabular}{ll}
\hline LLD & $1.43 \mu \mathrm{g} / \mathrm{L}$ \\
Estimated $\mathrm{MDL}_{\mathrm{s}}$ & $=5 \times 1.43=7.15 \mu \mathrm{g} / \mathrm{L}-7 \mu \mathrm{g} / \mathrm{L}$ \\
Blank & 0.0000 \\
Replicate \# & Found concentration \\
1 & 6.2 \\
2 & 6.4 \\
3 & 6.3 \\
4 & 6.4 \\
5 & 6.0 \\
6 & 6.1 \\
7 & 6.1 \\
Mean $_{\text {STDEV }}$ & 6.2 \\
MDL $_{\mathrm{s}}=3.14 \times$ STDEV & 0.1574 \\
\hline
\end{tabular}

B. If some give numerical results, then $M D L_{B}$ equals the highest method blank result.

C. If all of the method blanks give numerical results, calculate $\mathrm{MDL}_{\mathrm{B}}$ as

$$
\mathrm{MDL}_{\mathrm{B}}=\mathrm{X}+\left(3.14 \times \mathrm{STDEV}_{\mathrm{B}}\right)
$$

where $X=$ mean of blank results (set negative values to 0 ), and $S_{B}$ is a standard deviation of blank results.

The MDL then equals whichever is greater: $\mathrm{MDL}_{s}$ or $\mathrm{MDL}_{\mathrm{B}}$.

If we use more than 7 replicates, we should adjust the t value using Table 5 .

Both of IDL and MDL must be determined firstly before implementing the method.

Frequency Repeated annually or on an ongoing basis (or other specified frequency) for each analyte and major matrix or whenever the instrument configuration changes or major maintenance occurs, whichever happens first. Perform or verify MDL determination for each analyst and instrument, as well as whenever significant modification to the method's instrument or operating conditions also modifies detection or chemistry. Include all sample-preparation steps in the MDL determination.

5.4 Reporting level (RL) or level of quantitation (LOQ) or minimum quantifiable level (MQL)

Definition It is the analyte concentration that produces a signal sufficiently stronger than the blank, such that it can be detected with a specified level of reliability during routine operations. By another meaning, it is the smallest
Table 5 Student $\mathrm{t}$ table with conjugated replicates number and degree of freedom

\begin{tabular}{lll}
\hline Replicate \# & Degrees of freedom & t value at 0.99 \\
\hline 3 & 2 & 6.965 \\
4 & 3 & 4.541 \\
5 & 4 & 3.747 \\
6 & 5 & 3.365 \\
7 & 6 & 3.143 \\
8 & 7 & 2.998 \\
9 & 8 & 2.896 \\
10 & 9 & 2.821 \\
\hline
\end{tabular}

concentration of an analyte in the sample which can be detected by the detector and it can be determined quantitatively with appropriate precision and accuracy $[42,43]$.

\section{Preparation and determination}

1. Typically, it is the concentration that produces a signal $10 \times \operatorname{STDEV}_{B}$ above the reagent water blank signal "on the base of LOD calculation method" and it should have a defined precision and bias at that level [46]. So,

$\mathrm{LOQ}=10 \times \mathrm{STDEV}_{\mathrm{B}}$

2. LOQ can be determined by multiple samples of a standard "n samples" at near-zero concentrations (no more than five times the IDL). Then estimate the stand-

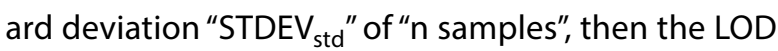
will be calculated as the following formula

$\mathrm{LOD}=10 \times \mathrm{STDEV}_{\text {std }}$

For example, if 20 determinations of a low-level standard yield a STDEV $=6 \mu \mathrm{g} / \mathrm{L}$, then the LOQ is $10 \times 6-60 \mu \mathrm{g} / \mathrm{L}$.

3. It can be expressed also, by statistical relationship as LOQ determination of chromatographic system [42, $43,47]$ as the following formula

$\mathrm{LOQ}=10 \times \sigma / \mathrm{S}$

where $\sigma$ is the standard error; $S$ is a slope of the linearity calibration curve.

4. Another method for LOQ determination can be used by Thermo Scientific [6] according to the following formula

$\mathrm{LOQ}=10 \times \sigma_{\mathrm{B}} \times \mathrm{Std}_{\text {conc }} /\left(\mathrm{R}_{\text {conc }}-\mathrm{R}_{\mathrm{B}}\right)$

$\sigma_{B}$ is the standard deviation of the intensities of the multiple blank measurements; $R_{\text {conc }}$ is the mean signal for the standard (prepared at concentrations 1,5 and $10 \mathrm{ppb}$ in $2 \%$ Nitric acid); $\mathrm{R}_{B}$ is the mean signal for the blank; $S_{\text {conc }}$ is the concentration of the standard. 
Although LOQ is useful in a laboratory, the practical quantitation limit $(\mathrm{PQL})$ has been proposed as the lowest level achievable among laboratories within specified limits during routine laboratory operations.

Frequency Repeated annually or whenever the instrument configuration changes or major maintenance occurs, whichever happens first.

The PQL is significant because different laboratories will produce different MDLs even when using the same analytical procedures, instruments, and sample matrices. The PQL, which is about three to five times larger than the MDL, is a practical and routinely achievable detection level with a relatively good certainty that any reported value is reliable.

\section{Linearity and calibration standards curve}

Definition The initial calibration is used to quantitate analytes of interest in samples, initial calibration was performed when the instrument is set up.

Preparation and determination Minimum a five standard calibration is recommended, for example; from 0 to $100 \mu \mathrm{g} / \mathrm{L}$ (ppb) including LOQ. Prepare all calibration standards and blanks in a matrix of $2 \%$ nitric acid. The same ratio of the internal standard should be mixed with all standards and blanks used in this method to provide appropriate count rates for interference correction.

Acceptance criteria Apply response-factor or linear curvefitting statistics to analyze the concentration vis instrument response relationship.

Response factor of the analyte of interest (RF)

$=$ Analyte response (A)/Analyte concentration (C)

If the relative standard deviation (\% RSD) of the response factors is $\leq 15 \%$, then the average response factor may be used. Otherwise, use a regression equation. The appropriate linear or nonlinear correlation coefficient for a standard concentration-to-instrument response should be $\geq 0.995$ for linear calibrations [45].

Frequency One time each run per working day or as method specification.

7. Linear dynamic range (LDR)
Definition and determination It is the maximum analyte concentration above the highest calibration point at which the analyte response is within $\pm 10 \%$ of its theoretical response. When determining LDRs, avoid using unnecessarily high analyte concentrations because they might damage the detector. It must be determined for all method analytes, including multi-element mixtures (to account for possible inter-element effects). LDR should be determined at the first method implementation.

Frequency Repeated annually.

8. Low-level standards

Definition and determination Both of $0.3-$ and a $1.0 \mu \mathrm{g} / \mathrm{L}$ "ppb" standard is used; when expected analyte concentration is less than $5 \mu \mathrm{g} / \mathrm{L}$. Prepare both standards in $2 \%$ nitric acid.

Frequency Repeated weekly or may be demanded in the calibration curve from the first.

9. Accuracy and precision: initial demonstration of capability (IDC)

Definition Each chemist in the laboratory should conduct an IDC at least once before analyzing any sample to demonstrate proficiency in performing the method and obtaining acceptable results for each analyte.

The IDC also is used to demonstrate that a laboratory's modifications to a method will produce results as precise and accurate as those produced by the reference method. As a minimum, include a reagent blank and at least four LFBs at a concentration between one and four times of the LOQ (or other level specified in the method).

Preparation and determination It was conducted after the successful implementation of the calibration curve. For each concentration; conduct at least 20 data points over different days.

Acceptance criteria Accuracy and precision (expressed as recovery percent) [45]: $\pm 20 \%$ as RSD $\%$,

Lower control limit $=$ Mean $-3 \times$ STDEV

Upper control limit $=$ Mean $+3 \times$ STDEV

- Mean is the average concentration of 20 data points. 
- STDEV is the standard deviation of 20 data points.

10. Continuing calibration verification (CCV)/calibration verification standard (CVS)

Definition Chemists periodically use a calibration standard to confirm that instrument performance has not changed significantly since initial calibration.

Preparation and determination Preferable to prepare a midrange standard in $2 \% \mathrm{HNO}_{3}$, with equivalent addition of internal standard using a different source than that used for the calibration standards. May be used the initial calibration to quantitate analytes of interest in samples.

Acceptance criteria The results must be within allowable deviations (within $\pm 10 \%$ of its true value) from either initial-calibration values or specific points on the calibration curve [5].

Note If the CCV is out of control, then take corrective action including re-analysis of any samples analyzed since the last acceptable CCV.

Frequency At least one per batch or after every 10 samples.

11. Laboratory-fortified blank (LFB)/ongoing demonstration of capability (ODC)/laboratory control sample (LCS)/QC check sample (QCCS)/blank spike (BS)

Aims They are used to ensure that the laboratory analysis remains in control while samples are analyzed and separate laboratory performance from method performance on the sample matrix. Sometimes laboratory control sample (LCS), is used to validate digestion techniques and known-addition levels.

Definition It is a method blank that has been fortified with a known concentration of the analyte to evaluate ongoing laboratory performance and analyte recovery in the clean matrix.

Preparation and determination Prepare fortified concentrations approximating the midpoint of the calibration curve

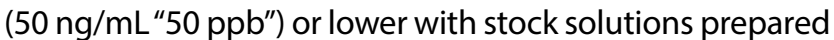
from a different source than that used to develop working standards. Or use an added concentration of at least $10 \times$ LOQ.

\section{SN Applied Sciences}

Calculate percent recovery, plot control charts, and determine control limits for these measurements. Ensure that the LFB meets the method's performance criteria when such criteria are specified.

Acceptance criteria Limits should be within $\pm 30 \%$ of true value based on analysis of at least 20 replicates [5].

Frequency At least one per batch or after every 10 samples.

12. Laboratory-fortified matrix (recovery of the analyte)/ analyte matrix effect

Definition It is an additional portion of a sample to which a known amount of the analyte(s) of interest is added before sample preparation. The LFM is used to evaluate analyte recovery in a sample matrix.

Preparation and determination It was conducted by adding a concentration that is at least $10 \times \mathrm{LOQ}$ or less than or equal to the midpoint of the calibration curve, or as in method-specified level to the selected sample(s). The chemist should use the same concentration as for LFB from the same reference source to allow the chemist to separate the matrix's effect from laboratory performance.

Frequency At least one per batch or after every 10 samples.

\section{Known-addition solution for samples}

Aim Method performance check.

Preparation and determination Add stock standard to sample so the volume change is less than $5 \%$. In the absence of information on analyte levels in the sample, prepare known additions at around $50 \mu \mathrm{g} / \mathrm{L}$ " $50 \mathrm{ppb}$ " or lower. If analyte concentration levels are known, add at $50-200 \%$ of the sample levels. For samples undergoing digestion, make additions before digestion. For dissolved metals determinations, make additions after filtration, preferably immediately before analysis.

Acceptance criteria Mean recovery $75-125 \%$ of spiked addition, RSD $\% \pm 20 \%$ for at least 20 replicates [5].

\subsection{Method validation parameters}

To validate the analysis method; some of the parameters should be performed as mentioned previously such as: 
Table 6 Suggested sequence with acceptance criteria

\begin{tabular}{ll}
\hline Item name & Acceptance criteria \\
\hline Tuning/optimization standard & As manufacturer limits \\
Rinse & - \\
Reagent blank & $<$ LOQ \\
Calibration curve (5 points), preffered concentarions $(0.1-$ & RSD $\%$ of RF $\leq 15.0 \%$ or $\mathrm{R}^{2} \geq 0.995$ \\
$\quad 100 \mathrm{ppb}$ ( $0.1 \mathrm{ppb}, 5 \mathrm{ppb}, 10 \mathrm{ppb}, 50 \mathrm{ppb}$ and $100 \mathrm{ppb})$ & \\
Internal standard response & $80-120 \%$ of response in Reagent blank \\
Rinse & - \\
Calibration verification about $(50 \mathrm{ppb})$ & $\pm 10 \%$ of true value \\
Rinse & - \\
QC check solution about $(0.1,50 \mathrm{ppb})$ & $\pm 20 \%$ of true value \\
Rinse & - \\
Unknown samples (10) & - \\
Rinse & - \\
Reagent blank & $<$ LOQ \\
Calibration verification about $(50 \mathrm{ppb})$ & $\pm 10 \%$ of true value \\
Rinse & - \\
Unknown samples (10) & - \\
Calibration verification about $(50 \mathrm{ppb})$ & $\pm 10 \%$ of true value \\
Rinse & - \\
\hline
\end{tabular}

1. LOD

2. LOQ

3. Linearity and range (calibration curve)

4. Accuracy and recovery

5. Repeatability and precision "performed at different concentrations of standards at the same day at least 3-10 replicates"

6. Ruggedness (Inter-precision) "performed at different concentrations of standards at least 10 data points over different days"

\subsection{Sample introduction}

- Samples at high total dissolved solids (TDS) concentration above $0.1 \mathrm{wt}$.\% must be avoided to use and further dilution is needed.

- Preparation of liquid samples is preferred in $2 \% \mathrm{v} / \mathrm{v}$ of $\mathrm{HNO}_{3}$.

- Filtration through $0.45 \mu \mathrm{m}$ diameter is preferred.

- The ultra-sonic bath should be used before the introduction of the samples to work.

- For solid samples, digestion in strong and hot acids is the typical protocol. The acids themselves range from simple nitric acid (for relatively simple matrices) to hydrofluoric acid (for samples containing high silicon dioxide content). Samples containing organic matter may also have hydrogen peroxide added to them during the digestion step because $\mathrm{H}_{2} \mathrm{O}_{2}$ breaks down organic matter efficiently.
- Solid samples can also be directly turned into aerosols several different ways, the most common being laser ablation (LA), spark ablation, or electrothermal vaporization (ETV). In all of these methods, the samples are converted to an aerosol and transported to the plasma with inert gas.

- ETV is a bulk analysis method that interacts with the entire sample and is useful for combustible samples. Spark ablation is a semi-bulk analysis tool and is useful for sampling large spots (1-3 $\mathrm{mm}$ diameter) of a conducting sample. LA is a microanalysis technique using high irradiance (UV) lasers to analyze very small spots (2-750 $\mu \mathrm{m}$ in diameter) on virtually all solid samples. Because of the small spot sizes, LA is also useful for tracking element distribution in a sample.

- If testing for Bromide or lodide, 0.1\% ammonium hydroxide $\left(\mathrm{NH}_{4} \mathrm{OH}\right)$ should be added [48].

A suggested sequence with acceptance criteria for quantitative analysis for routine work will be presented as the following in Table 6.

Acknowledgements The author presents great thanks to Smart Pharma Company and New Valley University for supporting this work.

\section{Compliance with ethical standards}

Conflict of interest The corresponding author states that there is no conflict of interest. 


\section{References}

1. Batsala M, Chandu B, Sakala B, Nama S, Domatoti S (2012) Inductively coupled plasma mass spectrometry (ICP-MS). Int J Res Pharm Chem 2:671-680

2. Ramyalakshmi GVP, Hepcy Kalarani D, Ravindra Reddy K, Archana E, Manjuvani S (2012) A review on inductively coupled plasma mass spectroscopy. Int Res J Drug Dev Res 4:69-79

3. Koch J, Günther D (2011) Review of the state-of-the-art of laser ablation inductively coupled plasma mass spectrometry. Appl Spectrosc 65:155A-162A

4. Feldmann J, Grümping R, Hirner AV (1994) Determination of volatile metal and metalloid compounds in gases from domestic waste deposits with GC/ICP-MS Fresen. J Anal Chem 350:228-234

5. Baird RB, Eaton AD, Rice EW (eds) (2017) Metals by inductively coupled plasma-mass spectrometry. In: Standard methods for the examination of water and wastewater, 3rd edn. American Public Health Association, American Water Works Association, Water Environment Federation, pp 1-10

6. Vincent T (2017) Thermo scientific iCAP RQ ICP-MS: typical limits of detection. Thermo scientific, pp 1-6

7. Mitrano DM, Barber A, Bednar A, Westerhoff $P$, Higgins $C P$, Ranville JF (2012) Silver nanoparticle characterization using single particle ICP-MS (SP-ICP-MS) and asymmetrical flow field flow fractionation ICP-MS (AF4-ICP-MS). J Anal Atom Spectrom 27:1131-1142

8. Fréchette-Viens L, Hadioui M, Wilkinson KJ (2019) Quantification of $\mathrm{ZnO}$ nanoparticles and other $\mathrm{Zn}$ containing colloids in natural waters using a high sensitivity single particle ICP-MS. Talanta 200:156-162

9. Taboada-López MV, Herbello-Hermelo P, Domínguez-González R, Bermejo-Barrera P, Moreda-Piñeiro A (2019) Enzymatic hydrolysis as a sample pre-treatment for titanium dioxide nanoparticles assessment in surimi (crab sticks) by single particle ICP-MS. Talanta 195:23-32

10. Junk T, Rehkämper M, Laycock AJ (2019) High-sensitivity tracing of stable isotope labeled Ag nanoparticles in environmental samples using MC-ICP-MS. J Anal Atom Spectrom 34:1173-1183

11. Chen $Z$, Chen B, He M, Wang H, Hu B (2019) A porous organic polymer with magnetic nanoparticles on a chip array for preconcentration of platinum(IV), gold(III) and bismuth(III) prior to their on-line quantitation by ICP-MS. Microchim Acta 186:107

12. Hoang QD, Kunihiro $T$, Sakaguchi $C$, Yamanaka $M$, Kitagawa $H$, Nakamura E (2019) Determination of abundances of fifty-two elements in natural waters by ICP-MS with freeze-drying preconcentration. Geostand Geoanal Res 43:147-161

13. Hendriks L, Ramkorun-Schmidt B, Gundlach-Graham A, Koch J, Grass RN, Jakubowski N, Günther D (2019) Single-particle ICPMS with online microdroplet calibration: toward matrix independent nanoparticle sizing. J Anal Atom Spectrom 34:716-728

14. Müller J-C, Horstmann $M$, Traeger $L$, Steinbicker AU, Sperling $M$, Karst U (2019) MXRF and LA-ICP-TQMS for quantitative bioimaging of iron in organ samples of a hemochromatosis model. J Trace Elem Med Biol 52:166-175

15. Fetter $N$, Blichert-Toft J, Télouk $P$, Albarède $F$ (2019) Extraction of $\mathrm{Pb}$ and $\mathrm{Zn}$ from crude oil for high-precision isotopic analysis by MC-ICP-MS. Chem Geol 511:112-122

16. Zhang SY, Zhang HL, Hou Z, lonov DA, Huang F (2019) Rapid determination of trace element compositions in peridotites by LA-ICP-MS using an albite fusion method. Geostand Geoanal Res 43:93-111

17. Heitland P, Köster HD (2006) Biomonitoring of 30 trace elements in urine of children and adults by ICP-MS. Clin Chim Acta 365:310-318
18. Townsend AT, Miller KA, McLean S, Aldous S (1998) The determination of copper, zinc, cadmium and lead in urine by high resolution ICP-MS. J Anal Atom Spectrom 13:1213-1219

19. Galusha AL, Haig AC, Bloom MS, Kruger PC, McGough A, Lenhart N, Wong R, Fujimoto VY, Mok-Lin E, Parsons PJ (2019) Ultra-trace element analysis of human follicular fluid by ICP-MS/MS: preanalytical challenges, contamination control, and matrix effects. J Anal Atom Spectrom 34:741-752

20. Schütz A, Bergdahl IA, Ekholm A, Skerfving S (1996) Measurement by ICP-MS of lead in plasma and whole blood of lead workers and controls. Occup Environ Med 53:736-740

21. Goullé J-P, Mahieu L, Castermant J, Neveu N, Bonneau L, Lainé G, Bouige D, Lacroix C (2005) Metal and metalloid multi-elementary ICP-MS validation in whole blood, plasma, urine and hair: reference values Forensic. Sci Int 153:39-44

22. Nunes JA, Batista BL, Rodrigues JL, Caldas NM, Neto JA, Barbosa $\mathrm{F}$ Jr (2010) A simple method based on ICP-MS for estimation of background levels of arsenic, cadmium, copper, manganese, nickel, lead, and selenium in blood of the Brazilian population. J Toxicol Environ Health A 73:878-887

23. Grassin-Delyle $S$, Martin M, Hamzaoui O, Lamy E, Jayle C, Sage E, Etting I, Devillier P, Alvarez J-C (2019) A high-resolution ICPMS method for the determination of 38 inorganic elements in human whole blood, urine, hair and tissues after microwave digestion. Talanta 199:228-237

24. Grønbæk-Thorsen F, Stürup S, Gammelgaard B, Møller LH (2019) Development of a UPLC-IDA-ICP-MS/MS method for peptide quantitation in plasma by Se-labelling, and comparison to S-detection of the native peptide. J Anal Atom Spectrom 34:375-383

25. Muller AL, Mello PA, Mesko MF, Duarte FA, Dressler VL, Muller El, Flores EM (2012) Bromine and iodine determination in active pharmaceutical ingredients by ICP-MS. J Anal Atom Spectrom 27:1889-1894

26. Lewen N, Mathew S, Schenkenberger M, Raglione T (2004) A rapid ICP-MS screen for heavy metals in pharmaceutical compounds. J Pharm Biomed Anal 35:739-752

27. Rao RN, Talluri MK (2007) An overview of recent applications of inductively coupled plasma-mass spectrometry (ICP-MS) in determination of inorganic impurities in drugs and pharmaceuticals. J Pharm Biomed Anal 43:1-13

28. Tokalıoğlu Ş (2012) Determination of trace elements in commonly consumed medicinal herbs by ICP-MS and multivariate analysis. Food Chem 134:2504-2508

29. Nardi EP, Evangelista FS, Tormen L, Saint TD, Curtius AJ, de Souza SS, Barbosa F Jr (2009) The use of inductively coupled plasma mass spectrometry (ICP-MS) for the determination of toxic and essential elements in different types of food samples. Food Chem 112:727-732

30. Eckhoff KM, Maage A (1997) lodine content in fish and other food products from East Africa analyzed by ICP-MS. J Food Compost Anal 10:270-282

31. Munro S, Ebdon L, McWeeny D (1986) Application of inductively coupled plasma mass spectrometry (ICP-MS) for trace metal determination in foods. J Anal Atom Spectrom 1:211-219

32. Tokalıoğlu Ş, Dokan FK, Köprü S (2019) ICP-MS multi-element analysis for determining the origin by multivariate analysis of red pepper flakes from three different regions of Turkey Lebensm. Wiss Technol 103:301-307

33. Durrant SF, Ward NI (2005) Recent biological and environmental applications of laser ablation inductively coupled plasma mass spectrometry (LA-ICP-MS). J Anal Atom Spectrom 20:821-829 
34. Chiang H-W, Lu Y, Wang X, Lin K, Liu X (2019) Optimizing MC-ICPMS with SEM protocols for determination of $U$ and Th isotope ratios and 230Th ages in carbonates. Quat Geochronol 50:75-90

35. Zhang N, Suleiman JS, He M, Hu B (2008) Chromium(III)imprinted silica gel for speciation analysis of chromium in environmental water samples with ICP-MS detection. Talanta 75:536-543

36. Cairns W, Ranaldo M, Hennebelle R, Turetta C, Capodaglio G, Ferrari C, Dommergue A, Cescon P, Barbante C (2008) Speciation analysis of mercury in seawater from the lagoon of Venice by online pre-concentration HPLC-ICP-MS. Anal Chim Acta 622:62-69

37. Farkas J, Peter $\mathrm{H}$, Christian P, Urrea JAG, Hassellöv M, Tuoriniemi J, Gustafsson S, Olsson E, Hylland K, Thomas KV (2011) Characterization of the effluent from a nanosilver producing washing machine. Environ Int 37:1057-1062

38. Buchberger WW (2007) Novel analytical procedures for screening of drug residues in water, waste water, sediment and sludge. Anal Chim Acta 593:129-139

39. McBride MB, Spiers G (2001) Trace element content of selected fertilizers and dairy manures as determined by ICP-MS. Commun Soil Sci Plant Anal 32:139-156

40. Khater AEM (2008) Uranium and heavy metals in Phosphate Fertilizers. In: Merkel BJ, Hasche-Berger A (eds) Uranium, mining and hydrogeology. Springer, Berlin, Heidelberg

41. Freije-Carrelo L, García-Bellido J, Calderon-Celis F, Moldovan M, Encinar JR (2019) GC-ICP-MS/MS instrumental set-up for total and speciation sulfur analysis in gasolines using generic standards. Anal Chem 91:7019-7024

42. Al-Hakkani MF (2019) A rapid, developed and validated RP-HPLC method for determination of azithromycin SN. Appl Sci 1:222
43. Al-Hakkani MF (2019) Forced degradation study with a developed and validated RP-HPLC method for determination of cefpodoxime proxetil in the bulk and finished pharmaceutical products. J Iran Chem Soc 16:1571-1578

44. Sheppard BS, Shen W-L, Davidson TM, Caruso JA (1990) Heliumargon inductively coupled plasma for plasma source mass spectrometry. J Anal Atom Spectrom 5:697-700

45. Baird RB, Eaton AD, Rice EW (eds) (2017) Quality assurance/quality control. In: Standard methods for the examination of water and wastewater, 3rd edn. American Public Health Association, American Water Works Association, Water Environment Federation, pp 1-4

46. Baird RB, Eaton AD, Rice EW (eds) (2017) Data quality. In: Standard methods for the examination of water and wastewater, 3rd edn. American Public Health Association, American Water Works Association, Water Environment Federation, pp 1-8

47. Gupta PC, Elanchezhiyan A, Shukla SC, Sengar AS, Saha A, Surendran R, Awasthi NP, Prasanth KP, Jacob S, Saxena SK (2019) Development, validation, and accreditation of a method for the determination of $75 \mathrm{As}, 111 \mathrm{Cd}, 201 \mathrm{Hg}$, and $208 \mathrm{~Pb}$ in Cephalopods using inductively coupled plasma mass spectrometry (ICPMS) SN. Appl Sci 1:304

48. Skoog D, Holler F, Crouch S (2007) Principles of instumental analysis, vol 47. Brooks/Cole, Cengage Learning Belmont, pp 2-11

Publisher's Note Springer Nature remains neutral with regard to jurisdictional claims in published maps and institutional affiliations. 